\title{
High Resolution Imaging Science Experiment (HiRISE) images of volcanic terrains from the first 6 months of the Mars Reconnaissance Orbiter Primary Science Phase
}

\author{
Laszlo Keszthelyi, ${ }^{1}$ Windy Jaeger, ${ }^{1}$ Alfred McEwen, ${ }^{2}$ Livio Tornabene, ${ }^{2}$ \\ Ross A. Beyer, ${ }^{3,4}$ Colin Dundas, ${ }^{2}$ and Moses Milazzo ${ }^{2,5}$ \\ Received 19 July 2007; revised 26 October 2007; accepted 10 January 2008; published 24 April 2008.
}

[1] In the first 6 months of the Mars Reconnaissance Orbiter's Primary Science Phase, the High Resolution Imaging Science Experiment (HiRISE) camera has returned images sampling the diversity of volcanic terrains on Mars. While many of these features were noted in earlier imaging, they are now seen with unprecedented clarity. We find that some volcanic vents produced predominantly effusive products while others generated mostly pyroclastics. Flood lavas were emplaced in both turbulent and gentle eruptions, producing roofed channels and inflation features. However, many areas on Mars are too heavily mantled to allow meter-scale volcanic features to be discerned. In particular, the major volcanic edifices are extensively mantled, though it is possible that some of the mantle is pyroclastic material rather than atmospheric dust. Support imaging by the Context Imager (CTX) and topographic information derived from stereo imaging are both invaluable in interpreting the HiRISE data.

Citation: Keszthelyi, L., W. Jaeger, A. McEwen, L. Tornabene, R. A. Beyer, C. Dundas, and M. Milazzo (2008), High Resolution Imaging Science Experiment (HiRISE) images of volcanic terrains from the first 6 months of the Mars Reconnaissance Orbiter Primary Science Phase, J. Geophys. Res., 113, E04005, doi:10.1029/2007JE002968.

\section{Introduction}

[2] The HiRISE camera provides an unprecedented combination of spatial resolution, color information, and coverage of the surface of Mars. The ground sampling distance (i.e., pixel dimension) is as small as $25 \mathrm{~cm}$, allowing 1-m-diameter objects to be well resolved. Typically, a 20,000 pixel $(\sim 6 \mathrm{~km})$ wide image is collected through a broad band-pass red filter, while the central 4000 pixel $(\sim 1.2 \mathrm{~km})$ swath is simultaneously imaged through a blue-green and a near-infrared filter. Thus three-band false color images can be constructed over the central $\sim 20 \%$ of each image. The MRO spacecraft is able to roll up to $30^{\circ}$ across track, allowing essentially any part of Mars to be imaged from orbit every few weeks. Stereo coverage can therefore be completed before lighting conditions change significantly. Further details of the HiRISE camera and the MRO mission are provided by McEwen et al. [2007].

[3] The HiRISE science plan divides Mars science and exploration into 18 themes [McEwen et al., 2007]. Here we report on the initial results from the "Volcanic Processes" science theme. Most of the upper crust of Mars is thought to have had a volcanic origin, though much of it has been strongly

\footnotetext{
${ }^{1}$ U.S. Geological Survey, Flagstaff, Arizona, USA.

${ }^{2}$ Lunar and Planetary Laboratory, University of Arizona, Tucson, Arizona, USA.

${ }^{3}$ Carl Sagan Center at the SETI Institute, Mountain View, California, USA.

${ }^{4}$ Also at NASA Ames Research Center, Moffett Field, California, USA.

${ }^{5}$ Now at U.S. Geological Survey, Flagstaff, Arizona, USA.
}

Copyright 2008 by the American Geophysical Union. 0148-0227/08/2007JE002968\$09.00 modified by impact, eolian, aqueous, periglacial, and other geologic processes [e.g., Greeley and Schneid, 1991; Keszthelyi and McEwen, 2007]. For the study of Martian volcanism at HiRISE resolution, it is essential to find exposures where the primary volcanic morphology has not been significantly altered at the $\sim 1-\mathrm{m}$ scale. As we describe here, finding such outcrops is perhaps the single greatest challenge in the study of Mars volcanism with HiRISE.

[4] The broad theme of Mars volcanism encompasses a diverse range of volcanic processes. We have chosen to categorize this diversity into the following subthemes: (1) vents, (2) shield volcanoes, (3) flood lavas, and (4) water-lava interactions. Volcanic vents include fissures, small shields, cones, and the nearby effusive and explosive deposits. We place all major volcanic edifices under the shield volcano subtheme, including ones that may contain a substantial amount of pyroclastic material. Flood lavas encompass all large lava flows that are not located on a topographically recognizable volcanic edifice. Lava-water interactions cover a host of secondary processes, including hydrovolcanic and hydromagmatic explosions, as well as subaqueous and subice volcanism. Early results from that subtheme have already been reported by Jaeger et al. [2007] and Dundas et al. [2007] and will not be discussed here. In this paper, we focus on primary volcanic features, but significant processes that modify the primary volcanic surface at the meter scale will also be touched upon.

\section{Sampling Strategy}

[5] During the first 6 months of the Primary Science Phase (PSP) (orbits 1316-3536), the goal was to sample a 
diverse set of volcanic (and suspected volcanic) terrains. In the early part of PSP, the HiRISE targeting database contained just under 400 potential volcanic observations. Thirty of these were elevated to the top priority before the start of PSP to provide a broad sampling. After 6 months, we have successfully acquired 115 volcanic images, of which 11 were on the top priority list. Figure 1 shows the location of the initial images and Table 1 lists some relevant information about each observation.

[6] As detailed by McEwen et al. [2007], the HiRISE camera can be operated in a myriad of different modes. The camera uses 14 separate charge couple detectors (CCDs) that can be individually commanded. For the initial sampling, we favored a mode that binned the outer CCDs to a greater extent than the central CCDs. This means that resolution decreases in discrete steps away from the center of the final image product. This helped us identify the optimal resolution for each terrain type.

[7] As we gained experience with imaging volcanic terrains with HiRISE, we began to aggressively collect stereo pairs over high-priority targets, taking full advantage of the MRO spacecraft's ability to roll-off nadir. At the end of 6 months of PSP, we have 22 completed stereo pairs over volcanic targets. While quantitative digital elevation model production has only just started [Kirk et al., 2007], anaglyph production has been largely automated utilizing a series of programs from the U.S. Geological Survey's Integrated Software for Imagers and Spectrometers 3 (ISIS3) [Anderson et al., 2004; Becker et al., 2007].

[8] The HiRISE images are complemented by data from the MRO Context Imager (CTX) [Malin et al., 2007] and Compact Reconnaissance Imaging Spectrometer for Mars (CRISM) [Murchie et al., 2007]. In this paper we do not report on results from CRISM. However, we do utilize the CTX data acquired in support of HiRISE observations. CTX images are typically provided to the MRO project after radiometric calibration and map projection at a scale of $5 \mathrm{~m} /$ pixel. CTX acquires images in a pushbroom mode, collecting $\sim 6 \mathrm{~m} /$ pixel data across a $30 \mathrm{~km}$ swath from MRO's typical altitude of $300 \mathrm{~km}$. We have produced anaglyphs from the CTX data in a process analogous to HiRISE anaglyphs.

\section{Volcanic Vents}

[9] Mafic eruptions can be fed by either extended or localized sources. It is common for an eruption to start along a fissure segment and transition to one (or a few) isolated vent(s) with time [e.g., Wadge, 1981]. If the eruption is reinvigorated by a new episode, a new fissure segment can open; although a single point source can also feed multiple eruptive episodes. Earlier orbital imaging of Mars had identified a number of both fissure and point vents [e.g., Carr, 1980; Cattermole, 1986; Mouginis-Mark and Christensen, 2005]. In this section we report on the initial HiRISE observations of both types of vents.

\subsection{Fissure Vents}

[10] Early HiRISE observations of fissures have focused mostly on the Late Amazonian Cerberus Fossae volcanotectonic fissure system, of which four images were acquired. Two images (TRA_000827_1875 and PSP_001342_1910) show no evidence for the local effusion of lava. At those locations, the fissure cuts into hard rock, forming a steep-walled graben containing some isolated pinnacle-like horsts (Figure 2). The layers, fractured by irregular jointing, shed angular multimeter-scale boulders. The relatively blue (enhanced) color of material shed from the walls is consistent with a broadly basaltic composition. A third image shows a portion of the fissure system that may have been passively inundated by flood lavas and is discussed later (Figure 14).

[11] PSP_001408_1900 is the only image to date that covers an unmistakable example of a relatively recent volcanically active section of the Cerberus Fossae [Jaeger et al., 2007]. It is located at the head of a tributary for Athabasca Valles, which parallels the main channel for $\sim 175 \mathrm{~km}$ before merging with its distributary network. The image shows the Cerberus Fossae in the south, the flank of an old and cratered wrinkle ridge in the northwest, and smooth plains in between (Figure 3a).

[12] Small lobate flows embaying the wrinkle ridge to the north (Figure 3b) may mark the highstand of the lava at peak discharge. The flow would have reached this height only briefly because depressions are not filled. Instead, a relatively uniform thickness of flow material drapes these higher elevations. The surfaces of some distal lobes are covered with small pits [Jaeger et al., 2007] reminiscent of (but smaller than) those found on the surfaces of some flows inside recent impact craters. Those pits are interpreted to have resulted from volatile loss from the impact ejecta [Tornabene et al., 2007]. This suggests the alternative possibility that these most distal lobes are actually mudflows. Mobile wet sediment could have formed either if Athabasca Valles was carved by aqueous floods or if ice in the subsurface was melted by the heat of the volcanic eruption.

[13] Within this HiRISE image, the transition between these high-elevation flows and the smooth plains is covered by a bright deposit undergoing eolian erosion. This appears to be the remnant of a once extensive mantling deposit that is now only preserved in the lee of topographic obstacles and where indurated or armored by impact ejecta [Jaeger et al., 2007]. The smooth plains exhibit albedo variations in the form of kilometer-scale arcuate bands that are roughly concentric to the imaged section of the fissure. They bear some resemblance to ripples in a pond, even reflecting off of topographic obstacles. HiRISE reveals that the bands are the fronts of thin flows that traveled uphill (north) for a limited distance, as shown by MOLA topography. Crosscutting relationships show that they become stratigraphically higher (i.e., younger) to the south. This can be attributed to a waning flux in the eruption, wherein successive pulses emplaced flow fronts with progressively smaller radii closer to the source region [Jaeger et al., 2007].

[14] The exceedingly fluid nature of these flows is evident on the west edge of the image, where the traces of older flow fronts show through younger and stratigraphically higher flows. Shadow measurements indicate that the flow fronts are less than $1 \mathrm{~m}$ tall. Dark zones at the terminal edges of individual flows are due to local increases in surface roughness (Figure 3c). The gravity-driven reversal of flow direction at those locations may have disrupted the solidifying crusts, giving them a roughened texture [Jaeger et al., 2007]. 


\section{HiRISE Observations}

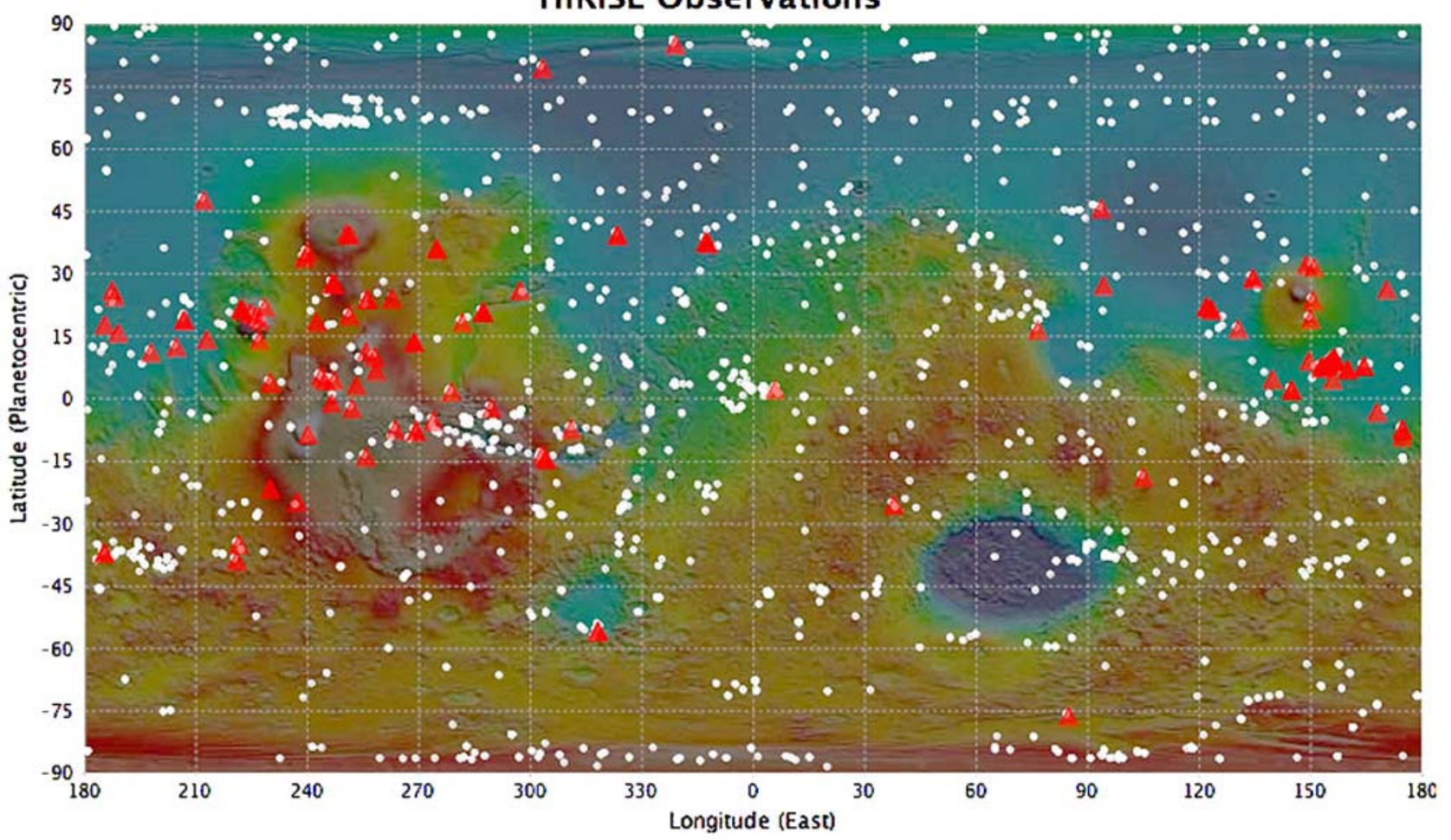

Figure 1. Location map of HiRISE images from the first 6 months of the Primary Science Phase. White circles are all observations, and red triangles are those with "volcanic processes" listed as either the primary or secondary science theme. Not all observations of volcanically interesting targets have red triangles because they were acquired under the aegis of nonvolcanic science themes. The distribution of images shows that we have met the goals (1) to sample a diversity of volcanic terrains and (2) to emphasize lava-water interactions. Since younger features are generally better preserved, there also is a bias toward Amazonian units.

[15] Narrow rifts zigzag across the plains, sometimes transecting flow fronts (Figure 3c). These fractures appear unrelated to the regional tectonics and instead are consistent with formation during the solidification of a coherent sheet flow. These rifts suggest that the fluid interiors of seemingly separate flows were once interconnected, allowing the entire sequence to deform as a unit. The sequence of flows appears to be a single cooling unit, as defined by Walker [1972].

[16] Within $2-3 \mathrm{~km}$ of the fissure, the plains gradually transition to a more irregular surface with knobs and broad channels. The topography is consistent with erosion by a fluid that was flowing back into the Cerberus Fossae (Figure 3d). It is very plausible that the lava was erosive this close to the massive lava fountains that must have fed the eruption. Alternatively, the lava could be draping flood-eroded topography. The hummocks of bright material may be local accumulations of pyroclastic material, but there is no evidence for spatter ramparts or other features often associated with fissure eruptions on Earth. The Cerberus Fossae reveals a stack of cliff-forming layers consistent with lava flows. However, the geologic context makes it likely that many, if not all, of these lavas exposed in cross section are from the Elysium volcanic rise and are unrelated to the lavas seen in plan view.

\subsection{Localized Vents}

[17] A number of low edifices marking localized sources of lava have been imaged to date (Table 1). East Mareotis
Tholus (Figure 4) is a somewhat unusual example, located in Tempe Terra, to the east of Alba Patera. The region is extensively fractured by volcano-tectonic fissures, including the Mareotis Fossae. The shield is remarkably smooth and devoid of boulders, even in crater ejecta and walls (Figure 4b). Lobate flows are also indiscernible. It is possible that a thick mantling layer has obscured all volcanic features. Indeed, these midlatitude regions of Mars are characterized by a volatile-rich mantling deposit [e.g., Mustard et al., 2001]. However, the lack of evidence for lava stratigraphy in the walls of a $0.73 \mathrm{~km}$ diameter impact crater, even where cleaned by mass wasting, suggests an alternative possibility. East Mareotis Tholus may be composed almost entirely of pyroclastic materials, broadly analogous to a terrestrial cinder cone. While a $\sim 6-\mathrm{km}$-diameter cinder cone is much larger than any terrestrial example, it is predicted that fountains on Mars would disperse material more extensively than on Earth; this is because of both the lower atmospheric pressure and the lower gravity [e.g., Wilson and Head, 1994; Fagents and Wilson, 1996].

[18] The elongated nature of the summit depression is uncommon for terrestrial cinder cones. The fact that it is parallel to the surrounding graben suggests that the volcanic vent was extended along a short fissure segment whose orientation was controlled by the local tectonic stresses. If so, it suggests that the eruption was not able to collapse 
Table 1. Successfully Acquired HiRISE Observations of Volcanic Targets From the First 6 Months of the Primary Science Phase

\begin{tabular}{|c|c|c|c|c|}
\hline Observation ID $^{\mathrm{a}}$ & Longitude & Latitude $^{\mathrm{b}}$ & Roll $^{\mathrm{c}}$ & Title \\
\hline PSP 0024821820 & 5.901 & 2.166 & 2.0 & Arabia West \\
\hline PSP $003193 \quad 1545$ & 37.870 & -25.729 & 6.1 & Sinus Crater Volcanic Flow \\
\hline PSP $002809^{-} 1965$ & 76.580 & 16.649 & 0.1 & NE Syrtis \\
\hline PSP_002928_1035 & 84.900 & -76.455 & 6.1 & Stripy polar markings as ice retreats \\
\hline PSP $002162^{-} 2260$ & 93.681 & 45.975 & 19.7 & Scalloped terrain \\
\hline PSP_001674_1610 & 105.026 & -18.997 & 5.0 & Sample High Thermal Inertia Area Northwest of Tyrrhena Patera \\
\hline PSP 0023592020 & 121.991 & 22.243 & -5.3 & Chain of Cratered Cones near Hephaestus Fossae \\
\hline PSP $003203^{-} 2020$ & 121.991 & 22.243 & -26.1 & Chain of Cratered Cones near Hephaestus Fossae \\
\hline PSP 0014622015 & 123.337 & 21.555 & 1.2 & Cratered cones near Hephaestus Fossae \\
\hline $\mathrm{PSP}^{-} 001792^{-} 2015$ & 123.337 & 21.555 & -19.7 & Cratered cones near Hephaestus Fossae \\
\hline PSP 0013431970 & 130.563 & 16.779 & -1.4 & Polygonal Crater Fill Surrounded by Smooth Plains \\
\hline PSP $002042^{-} 2090$ & 134.521 & 29.123 & 5.9 & Potential Lobe of Lahar Flow Front \\
\hline PSP_002108_2090 & 134.521 & 29.123 & -13.1 & Potential Lobe of Lahar Flow Front \\
\hline PSP $002411^{-} 1820$ & 144.879 & 2.022 & -6.1 & Ring/cone structures in Elysium Planitia north of Aeolis Planum \\
\hline PSP_002622_1820 & 144.879 & 2.022 & -13.2 & Ring/cone structures in Elysium Planitia north of Aeolis Planum \\
\hline PSP $001527^{-} 2125$ & 148.902 & 32.503 & 0 & Elliptical depression on lower northwest flank of Hecates Tholus \\
\hline PSP_003347_-1890 & 149.611 & 9.093 & 3.4 & Flow Margin in Cerberus Palus \\
\hline PSP 0034262035 & 150.661 & 23.749 & 7.5 & Intersection of Sinuous Rille and Pit Crater Chain on Elysium Mons \\
\hline PSP $003215^{-} 2120$ & 150.917 & 31.798 & -3.8 & Sample Hecates Tholus Stratigraphy with 4-km Diameter Impact Crater \\
\hline PSP $002147 \quad 1875$ & 152.807 & 7.488 & -19.0 & Small cones/mounds in channel cut by Zunil secondaries \\
\hline $\mathrm{PSP}^{-} 002292^{-} 1875$ & 152.807 & 7.488 & -3.6 & Small cones/mounds in channel cut by Zunil secondaries \\
\hline PSP_002648_1880 & 153.871 & 7.940 & -7.9 & Ring and Cone Structures atop Rafted Plates in Athabasca Valles \\
\hline PSP $002793-1885$ & 154.436 & 8.259 & 0 & Athabasca Main Channel \\
\hline PSP_002015_1880 & 154.891 & 8.051 & 0 & Athabasca Vallis system and associated landforms \\
\hline PSP $002938-1890$ & 155.306 & 8.996 & 4.3 & Sample Main Channel of Athabasca Valles \\
\hline PSP_003083_1890 & 155.306 & 8.996 & 20.2 & Sample Main Channel of Athabasca Valles \\
\hline $\mathrm{PSP}^{-} 001540^{-} 1890$ & 155.906 & 8.894 & 16.6 & Athabasca Valles distributary channel \\
\hline PSP $002371^{-} 1890$ & 155.906 & 8.894 & -4.0 & Athabasca Valles distributary channel \\
\hline PSP 0033601845 & 155.970 & 4.533 & -5.0 & Distal End of Lethe Vallis \\
\hline PSP $002661-1895$ & 156.330 & 9.702 & 20.1 & Ring and Cone Structures Dunes and Other Landforms in Athabasca Valles \\
\hline PSP 0032941895 & 156.330 & 9.702 & 4.4 & Ring and Cone Structures Dunes and Other Landforms in Athabasca Valles \\
\hline PSP $001606-1900$ & 156.423 & 9.767 & 4.9 & Field of morphologically diverse ring/cone structures in Athabasca Valles \\
\hline PSP 0022261900 & 156.423 & 9.767 & -25.7 & Field of morphologically diverse ring/cone structures in Athabasca Valles \\
\hline PSP $002806-1870$ & 159.969 & 7.009 & -3.5 & Summit of One of the Elysium Tholi \\
\hline PSP_003096_1870 & 159.969 & 7.009 & 27.3 & Summit of One of the Elysium Tholi \\
\hline PSP $003241^{-} 1880$ & 164.376 & 7.797 & -6.5 & Cerberus Fossae and Diverse Morphologies \\
\hline $\mathrm{PSP}^{-} 002542^{-} 1765$ & 167.896 & -3.284 & 8.7 & Fractured mounds at the southern edge of Elysium Planitia \\
\hline PSP 0023442065 & 170.520 & 26.348 & 0 & Mounds with summit pits in the Phlegra region \\
\hline $\mathrm{PSP}^{-} 001988^{-} 1710$ & 174.725 & -9.196 & -7.6 & Breach in channel along Apollineris Patera caldera \\
\hline PSP 0016451725 & 174.735 & -7.478 & 4.0 & North flank of Apollinaris Patera \\
\hline $\mathrm{PSP}^{-} 002634^{-} 1725$ & 174.735 & -7.478 & 29.1 & North flank of Apollinaris Patera \\
\hline PSP $001460-1425$ & 185.367 & -37.311 & 0.7 & Unconformable Deposits in Electris \\
\hline PSP_001724_1425 & 185.367 & -37.311 & -15.0 & Unconformable Deposits in Electris \\
\hline PSP_002027_1980 & 185.501 & 17.921 & 6.6 & Flow front of lava flow in Marte Vallis \\
\hline PSP 0033062060 & 187.517 & 26.186 & -4.8 & Cones on Lava Flows in the Tartarus Colles \\
\hline PSP_001420_2045 & 188.129 & 24.745 & 7.8 & Small channel winding between knobs in the Tartarus Colles \\
\hline PSP 0025281960 & 189.16 & 15.930 & -7.5 & Cone/hill in west Amazonis Planitia \\
\hline PSP $003398-1910$ & 197.967 & 11.158 & -6.4 & Bullseye Crater of MFF Over Platy-Ridged Lava \\
\hline PSP $002712-1925$ & 204.758 & 12.482 & 7.1 & Windows in a mantling deposit open onto a platy-ridged substrate \\
\hline $\mathrm{PSP}^{-} 003213^{-} 1990$ & 206.818 & 19.046 & 0.1 & Faulted Lava Flow in Amazonis Planitia \\
\hline PSP_001485_2280 & 212.198 & 48.008 & 0 & Two possible cratered cones \\
\hline PSP $001340-1945$ & 213.000 & 14.342 & -4.7 & Amazonis East \\
\hline PSP_003160_1410 & 220.973 & -39.134 & 2.2 & Relatively dust free lavas from Arsia Mons \\
\hline $\mathrm{PSP}^{-} 001960^{-} 1450$ & 221.578 & -35.235 & 4.7 & Relatively dust free lava flow eminating from Arsia Mons Daedalia Planum \\
\hline PSP_002118_2015 & 222.170 & 21.671 & -10.9 & Olympus Mons Basal Scarp-North \\
\hline PSP 0014322015 & 222.348 & 21.749 & -5.8 & Layers in Olympus Mons basal scarp \\
\hline PSP $001630-2015$ & 222.348 & 21.749 & -18.4 & Layers in Olympus Mons basal scarp \\
\hline PSP 0033312005 & 224.743 & 20.662 & 6.2 & Lava Fan on Olympus Mons \\
\hline PSP $002909^{-} 2000$ & 226.056 & 19.925 & 0 & Several fans associated with a flank terrace \\
\hline PSP_003476_1940 & 227.071 & 14.133 & 5.1 & Cross Section Through the Base of Southern Olympus Mons \\
\hline PSP $001920-1990$ & 227.204 & 18.936 & 0 & Characterize small craters on floor of relatively young caldera \\
\hline PSP_003199_2020 & 228.628 & 22.142 & -0.2 & Impact crater and possible related lava tube collapse features \\
\hline PSP $003331-1580$ & 230.015 & -21.839 & 6.3 & Daedalia Planum crater \\
\hline PSP_003410_1840 & 230.103 & 3.823 & 7.3 & Sample Gigas Fossae \\
\hline PSP_002711_1550 & 237.303 & -24.978 & 0 & Flow Margin Southeast of Arsia Mons \\
\hline PSP $003370-2140$ & 239.280 & 34.103 & -5.2 & Cyane Fossae \\
\hline PSP $002157 \quad 1715$ & 240.136 & -8.536 & 0 & Low shield volcano in caldera of Arsia Mons \\
\hline $\mathrm{PSP}^{-} 002737^{-} 1985$ & 242.582 & 18.619 & -6.2 & Jovis Tholus Caldera Wall \\
\hline PSP $001959-1855$ & 243.681 & 5.381 & 5.6 & Pavonis Mons northern flank deposits \\
\hline $\mathrm{PSP}^{-} 001682^{-} 1845$ & 244.773 & 4.313 & -5.3 & Radial ridge in Pavonis Mons 'aureole' \\
\hline PSP $002671^{-} 1790$ & 246.585 & -1.094 & -2.4 & Cone on Pavonis Mons \\
\hline PSP $002328-2080$ & 246.838 & 27.859 & 2.9 & Low shield with elongate summit depression in north Tharsis \\
\hline PSP_002605_2080 & 246.838 & 27.859 & -21.8 & Low shield with elongate summit depression in north Tharsis \\
\hline
\end{tabular}


Table 1. (continued)

\begin{tabular}{|c|c|c|c|c|}
\hline Observation $\mathrm{ID}^{\mathrm{a}}$ & Longitude & Latitude $^{\mathrm{b}}$ & Roll $^{\mathrm{c}}$ & Title \\
\hline PSP_001695_2080 & 246.941 & 27.896 & -2.1 & Flows and fractures in the northern part of the Tharsis rise \\
\hline PSP_001629_2080 & 247.121 & 27.897 & 0 & Flows and fractures in the northern part of the Tharsis rise \\
\hline PSP_002816_1840 & 247.223 & 4.220 & -2.5 & Pavonis Mons northern flank deposits \\
\hline $\mathrm{PSP}^{-} 002908^{-} 2200$ & 250.535 & 39.927 & 0 & Caldera of Alba Patera \\
\hline PSP_001840_2000 & 251.407 & 20.157 & -2.6 & Sample Pits and Graben in Tharsis \\
\hline PSP $001510-2195$ & 251.535 & 39.678 & 0 & Small-scale features on Alba Patera \\
\hline PSP_002117_1775 & 252.040 & -2.422 & -7.6 & Small volcano east/southeast of Pavonis Mons \\
\hline PSP $003185-1830$ & 253.193 & 3.185 & -0.1 & Shield near Ascraeus Mons \\
\hline PSP_001840_1660 & 255.779 & -14.056 & -5.0 & Lava Vent in Syria Planum \\
\hline PSP $001444-1915$ & 255.860 & 11.400 & -1.5 & Ascraeus Mons caldera wall \\
\hline PSP $002420-2040$ & 256.153 & 24.136 & -2.9 & Pit crater chain nested within graben at Tractus Catena \\
\hline PSP_002710_2040 & 256.153 & 24.136 & 23.6 & Pit crater chain nested within graben at Tractus Catena \\
\hline $\mathrm{PSP}^{-} 001853^{-} 1900$ & 258.198 & 10.051 & -8.6 & Dissected vent on the southern flank of Ascraeus Mons seen in THEMIS VIS \\
\hline PSP $002209-1865$ & 258.520 & 6.653 & 1.0 & Variety of lava flow types close to Ascreaus Mons \\
\hline PSP $002156^{-} 2040$ & 262.904 & 24.191 & 4.9 & Ceraunius Tholus \\
\hline PSP_001457_1725 & 263.747 & -7.477 & -4.3 & Floor of Noctus Labyrnthus \\
\hline PSP $002380-1935$ & 268.716 & 13.611 & 6.9 & Sample Tharsis Tholus Caldera wall \\
\hline PSP_002169_1940 & 268.760 & 13.755 & 12.3 & Tharsis Tholus \\
\hline PSP $001404-1720$ & 269.242 & -7.817 & 0.5 & Layered walls of Noctus Labyrinthus \\
\hline PSP_001734_1720 & 269.242 & -7.817 & -23.4 & Layered walls of Noctus Labyrinthus \\
\hline PSP_001483_1745 & 273.949 & -5.387 & 0 & Possible pyroclastic flows around catena rim Tithonia Catena \\
\hline PSP $001760-2160$ & 274.862 & 36.221 & -21.5 & East Mareotis Tholus \\
\hline PSP_001364_2160 & 274.862 & 36.230 & 1.1 & East Mareotis Tholus \\
\hline PSP $001430-1815$ & 278.867 & 1.642 & 0 & Eroding material over flows in Echus Chasma \\
\hline PSP_001509_1985 & 281.758 & 18.448 & 0 & Flow feature near Nilus Dorsa \\
\hline PSP 0014562010 & 287.189 & 20.905 & 0 & Flow margin within Kasei Valles \\
\hline PSP_002287_2010 & 287.344 & 21.002 & -0.3 & Kasei Vallis Cataract \\
\hline PSP $002788^{-} 2010$ & 287.344 & 21.002 & 21.1 & Kasei Vallis Cataract \\
\hline PSP_003276_1775 & 289.538 & -2.352 & 0 & Pit crater chain in Ganges Catena \\
\hline PSP_001482_2065 & 297.289 & 26.291 & 0 & Kasei Valles lava flow \\
\hline PSP_002814_1665 & 303.281 & -13.501 & 6.2 & Sidearm of Valles Marineris to trace strong layer \\
\hline PSP 0017322595 & 303.347 & 79.527 & -5.2 & Far northern cone \\
\hline PSP $002036-1655$ & 304.163 & -14.598 & 2.2 & Layered mesa in Coprates Chasma \\
\hline PSP_003104_1655 & 304.163 & -14.598 & 28.6 & Layered mesa in Coprates Chasma \\
\hline PSP $002550-1725$ & 311.022 & -7.335 & -4.4 & Survey layering and faulting in layered deposits Ganges Chasma \\
\hline PSP_001640_1240 & 318.221 & -56.146 & 3.0 & Sinuous Ridge in Argyre \\
\hline PSP $002457^{-} 2195$ & 323.439 & 39.595 & 2.2 & Light mounds in Acidalia \\
\hline PSP_002536_2195 & 323.439 & 39.595 & 27.5 & Light mounds in Acidalia \\
\hline PSP_001518_2650 & 338.920 & 85.088 & 13.6 & Chasma Boreale Scarp with Gypsum \\
\hline PSP $002232-2180$ & 347.266 & 37.904 & -5.5 & Dark crater-topped cones in Cydonia \\
\hline PSP 0023772180 & 347.266 & 37.904 & 6.7 & Dark crater-topped cones in Cydonia \\
\hline PSP & 347.965 & 37.571 & -0.5 & Sample Cones in Acidalia \\
\hline
\end{tabular}

aAll observation ID's have the following syntax: NNN_XXXXXX_YYYY where NNN is the mission phase code, XXXXXX is the orbit number, and YYYY is a representation of latitude. TRA designates the Transition Phase (October 2006), while PSP indicates the Primary Science Phase (started 8 November 2006 and continuing). Orbits are counted since Mars Orbit Insertion. The representation of latitude (YYYY), is measured from the equator on the descending side of the orbit. In this scheme, zero degrees is the descending (nightside) equator, which is where the orbit number increments. The south pole is at $90^{\circ}$, the ascending (dayside) equator is at $180^{\circ}$, and the north pole is at $270^{\circ}$. The latitude is specified to one decimal place, to the nearest half degree. Therefore, the last digit will always be either zero or 5 . For example, an image targeted at $11.3^{\circ} \mathrm{N}$ (on the dayside) will have an observation ID with the last four digits of 1915 .

${ }^{\mathrm{b}}$ Planetocentric north latitude (negative values are in the southern hemisphere).

${ }^{c}$ Positive roll angle is to the left. For most observations, the orbit is passing from south to north, so positive roll is to the west.

down to a single point, perhaps because the eruption duration was relatively short. If the eruption had been sustained longer, erosion of the dike walls and freezing of narrow parts of the dike would have allowed a more circular conduit to carry the entire magma flux [e.g., Wadge, 1981]. While the evidence is not conclusive, we suggest that East Mareotis Tholus is an example of a volcanic vent that produced mostly pyroclastic materials.

[19] In contrast, PSP_001629_2080, PSP_001695_2080, PSP_002605_2080, and PSP_002328_2080 cover a region that shows evidence for a diverse range of effusive volcanic landforms. These images come from the plains in the northern part of the Tharsis volcanic province, between three major sets of tectonic fractures: Cyane Fossae, Ceraunius Fossae, and Olympica Fossae. Figure 5a provides a regional view using CTX images. The main edifice is actually two coalesced low shields. Embayment relations are not entirely clear, but it appears that flows from the lower (eastern) shield overlie the flows from the taller structure. Flows from both sources cover long lava flows that entered the region from the east as well as various fractures in the northwest.

[20] Both shields have relatively deep troughs at their summits surrounded by shallower depressions with scalloped borders marked by narrow raised rims. The central troughs are interpreted as the collapse-widened volcanic conduits. Their orientations are probably strongly influenced by preexisting weaknesses in the crust. Because this area is close to 3 different sets of fractures, it is not surprising to see three different orientations for the volcanic 


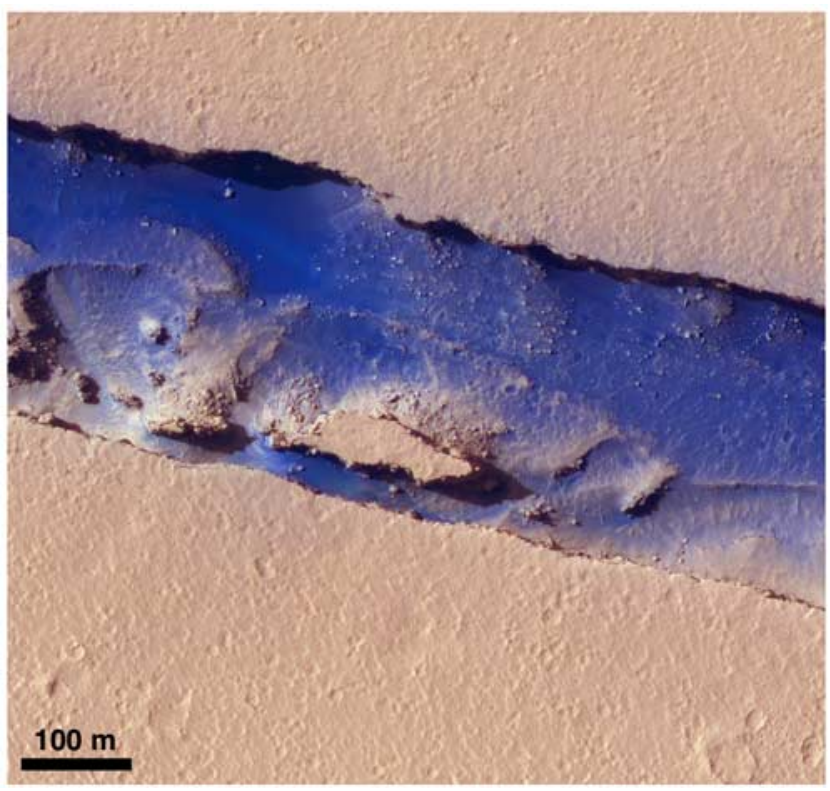

Figure 2. Portion of Cerberus Fossae in false color. Cutout from TRA_000827_1875 centered at $7.470^{\circ} \mathrm{N}, 168.536^{\circ} \mathrm{E}$. (All latitudes in this paper are planetocentric.) Red-greenblue (RGB) false color image produced by rendering the blue-green (BG) data in the blue channel, red in the green, and near-infrared (IR) in the red. The channels are then individually contrast enhanced to highlight the color variations. The essentially vertical walls of the fissure make it difficult to see layering in this nadir observation. For all images in this paper, north is to the top, and illumination is from the west.

conduits. The greater infilling of the western vent supports the idea that it is the older one. It is plausible that much of the infilling is pyroclastic material from lava fountains that probably played over the eastern vent.

[21] The shallower depressions are interpreted to be drained lava lakes. Many terrestrial lava lakes are not surrounded by steep levees such as are seen in Figure 5. However, 5-8 m tall, narrow, near-vertical levees confining a lava pond a few hundred meters across were observed forming on Kilauea Volcano, Hawaii during the period of 17-21 February 1992 [Heliker et al., 1998]. The levees were composed of small overflows that were emplaced as the pond level gradually increased in a series of small surges. Similar near-vent constructs were found on the Burfells lava flow in Iceland [Keszthelyi et al., 2004]. By analogy, small near-vent overflows are inferred to have formed the levees on the Martian examples seen in Figure 5.

[22] The western pond has a distinct breach in its levee, from which a fan of lava flows emanates (Figure 5b). It is likely that the $\sim 1 \mathrm{~km}$ long, $\sim 150 \mathrm{~m}$ wide channel that connects the breach to the lava fan was formed by mechanical erosion as the lava poured through the breach. The channel levees are probably produced by spillovers and stranded crust. The fan is composed of an intricate series of small channels with numerous breakouts, suggesting that it was constructed over an extended period of time. Therefore, it seems that the eruption continued for some time after the levee failure but never succeeded in rebuilding the levees and reestablishing a large lava lake at the summit. However, the preserved lava lake and lava fan are only the last chapter in what must have been a long-lived eruption that built up the low shield.

[23] The eastern vent structure appears to record an even more complex sequence of volcanic events. The main summit trough actually extends in three different directions. We suspect that the largest (east-west) trough is the primary volcanic vent. Once a lava lake had built up in elevation, the hydraulic head would have driven lava to exploit any subterranean weaknesses. The branch of the trough that extends to the southeast has built up wider levees than the main east-west trough. This could be the result of comparatively voluminous overflows driven by the enhanced hydrostatic pressure at this slightly lower elevation. The small mounds extending onward from this trough could be built up of small flows emanating from secondary vents fed by subsurface flow of lava from the lava lake. Much more voluminous lava flows emanate from the small, disconnected depression to the northeast. These may have formed as lava followed a fracture parallel to those seen to the west of the shields or they may mark a now-buried rift zone extending further to the northeast (Figure 5a).

[24] Perhaps the most interesting features associated with these vents are the long, sinuous channels. Without highresolution topographic data, these could be mistaken for erosional channels, perhaps even formed by fluvial processes. However, the new MRO data clearly show these to be constructional features, with levees and many overflows (Figure 5a). The channels exhibit both tributaries (near the vent) and distributaries. The channels also have isolated "islands" where the flow separated and rejoined a short distance downstream. There are hints that the largest channel (headed north from the eastern vent) suffered blockages, diversions, and overflows toward the end of its history. Near the major bend to the west, there is a side channel with overflows overlying the other flows, indicating that it was a late formed feature. Furthermore, at the bend, the channel is filled, perhaps as a result of lava backing up behind an obstruction. Major overflows feed to the north from this location, further hinting at a major blockage. This kind of breakdown of an established lava channel toward the latter part of an eruption is common on Earth (e.g., the 1984 Mauna Loa eruption [Lipman and Banks, 1987]).

[25] Overall, this vent complex shows that complex, longlived eruptions definitely occurred on Mars. Lava flows of this scale and morphology are well within historical terrestrial experience and are typically fed by eruptions of order $100-1000 \mathrm{~m}^{3} / \mathrm{s}$. Lava lakes a few kilometers in diameter are not common, but such activity persisted for many decades in Kilauea's caldera [Holcomb, 1987]. Unfortunately, the ubiquitous wind-eroded mantling deposit hides all meterscale volcanic features, frustrating our attempts to utilize HiRISE's full capabilities to draw further analogies. In this kind of terrain, CTX appears to provide the ideal mix of spatial resolution and coverage for optical imaging.

[26] Other small shields on volcanic plains, including an example of the Cerberus Tholi, show very similar features: perched, leveed lava lakes atop a segment of a fissure vent with a complex network of channelized lava flows extending radially outward. As with the Tharsis example, the region has sufficient eolian mantling to obscure meter-scale 

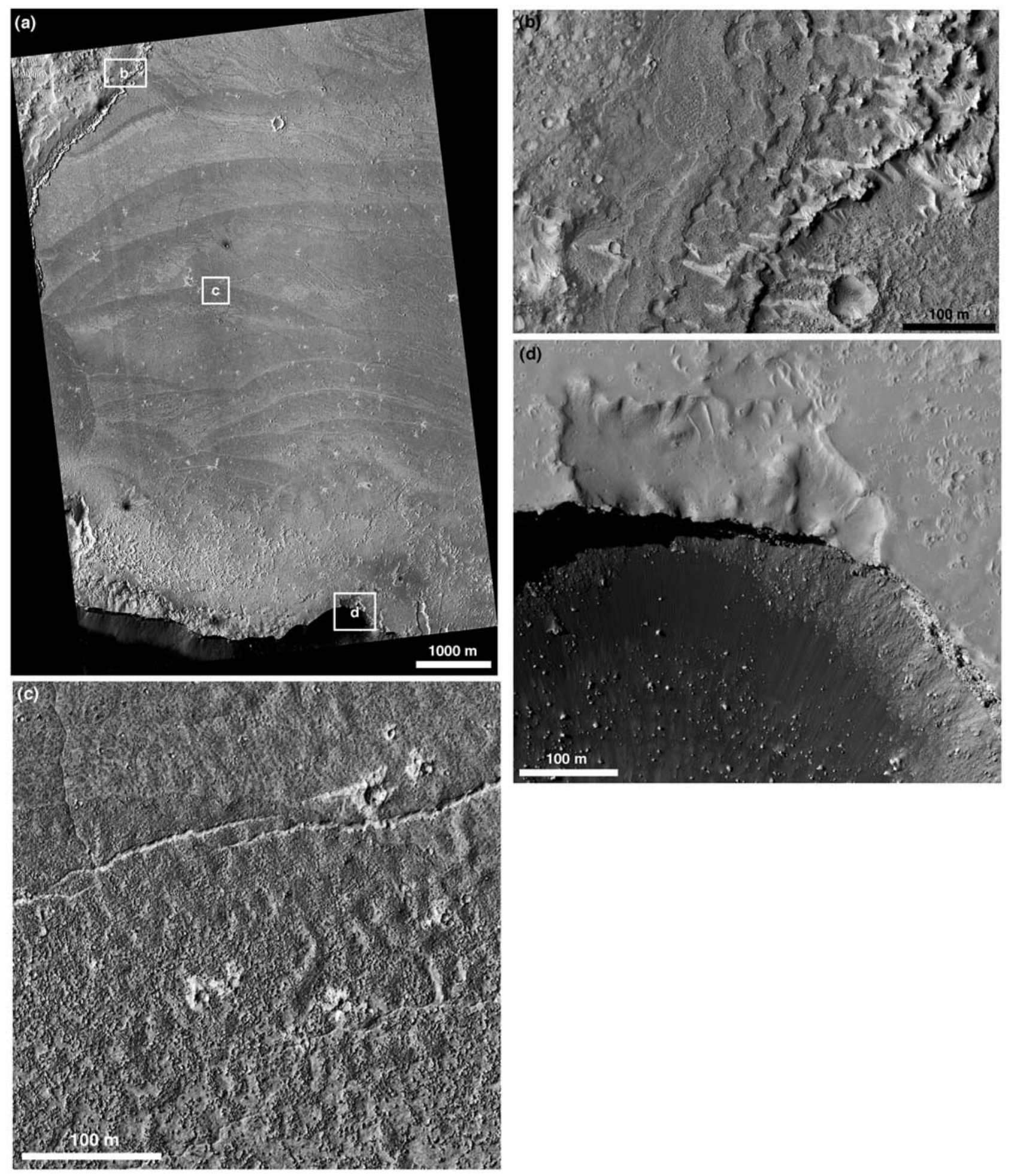

Figure 3. Lava vent along the Cerberus Fossae. (a) Browse view of HiRISE image PSP_001408_1900 centered at $10.024^{\circ} \mathrm{N}, 158.015^{\circ} \mathrm{E}$. A segment of the Cerberus Fossae can be seen in the south, an eroded wrinkle ridge in the northwest, and banded plains in between. (b) Close-up of the flow margin. Note the smooth and the rough surface textures of the distal flow lobes and the remnants of a bright mantling deposit at the base of the wrinkle ridge. (c) Close-up of the banded plains. The bands are flow fronts where the leading edge is composed of disrupted slabs of crust. The fractures cut across flow fronts, indicating that the whole sequence of flows deformed as a single unit. (d) Close-up of the fissure rim. Note the scalloped surface of the plains near the fissure, strongly suggestive of erosion. The walls of the fissure are composed of rocky layers consistent with lava flows. Because this area is covered by a uniform albedo coating of dust, special contrast enhancement has been used to highlight the morphologic features. 

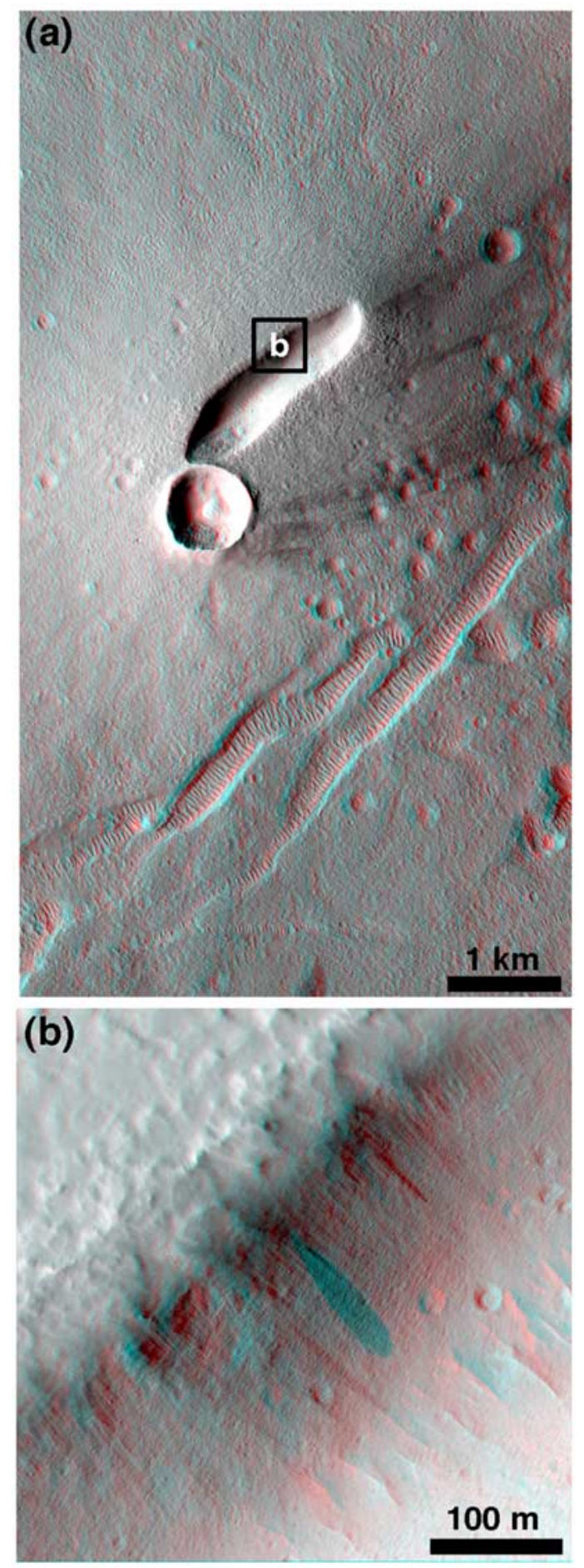

Figure 4. East Mareotis Tholus. (a) Anaglyph produced from HiRISE observations PSP 001364_2160 and PSP_001760_2160. The elongated central pit is the volcanic vent. The circular depression on the southwest is a superimposed impact crater. Evidence for lava flows, in the form of resistant layers and lobate scarps, are notably absent. Note the dune-filled graben south of the cone that are subparallel to the summit depression. (b) Close-up centered at $35.919^{\circ} \mathrm{N}, 274.864^{\circ} \mathrm{E}$ highlighting the lack of exposed boulders even in steep walls. The cyan streak in the center of the cutout is a new dark slope streak that formed between the time that the two HiRISE images were acquired. features, so CTX, with its wider coverage, proves more useful than HiRISE.

[27] Small, localized vents can also be found on the large shield volcanoes. Figure 6 shows examples of two different types of vents - depressions that feed sinuous channels and small cones. The sinuous rilles and associated pits are remarkably similar in form to lunar examples [e.g., Schubert et al., 1970]. While these are now known to be volcanic features [e.g., Hulme, 1982], it is important to recall that there were extensive quantitative geomorphologic and geophysical arguments pointing to water having been the erosive fluid that created lunar sinuous rilles [Schubert et al., 1970]. On Mars, there continues to be discussion of the roles of lava versus aqueous fluids in carving these features [e.g., Carr, 1974; Mouginis-Mark, 1990; Carr, 1996; Mouginis-Mark and Christensen, 2005].

[28] A relatively small example of a Martian sinuous rille is completely contained in the CTX image shown in Figure 6a. It starts from a breach in a nearly circular pit. This pit is indistinguishable from other pit craters in the area but does have a small inner pit that might be the actual volcanic vent. Similar (but smaller) pits are common on terrestrial basaltic volcanoes, forming as collapses over areas of local extension [Okubo and Martel, 1998]. As the sinuous rille extends for a little over $20 \mathrm{~km}$, it gradually changes character. Near the vent it is a single, deeply incised channel with a width of $\sim 250 \mathrm{~m}$ but by the terminus it is a diffuse series of shallow channels, each less than $100 \mathrm{~m}$ wide. Overflows of lobate, channelized lava flows become more frequent down the length of the rille until it becomes a broad lava fan. One characteristic that does not vary is that the rille remains flatfloored, without bars or other fluvial bed forms. This seems to be a very clear example of an erosional lava channel. We infer that the larger sinuous rilles formed by essentially the same process. Erosion by lava on this scale requires sustained very high eruption rates, preferably of hightemperature lavas [Hulme, 1973; Greeley et al., 1998; Williams et al., 2005].

[29] Unfortunately, HiRISE is not able to provide additional insight because the eolian mantling deposit obscures all the volcanic (and tectonic) features at the meter scale. At $2 \times 2$ binned HiRISE resolution, we find the area covered with dune forms (Figure 6b). Full resolution imaging of similar terrains has shown that the speckling seen at $2 \times 2$ binning is caused by ripples less than a meter in wavelength. As will be discussed in more detail in the next section, this thick layer of wind-transported material is ubiquitous on the major shield volcanoes.

[30] HiRISE does reveal new details about a small cone on the flanks of the volcano (Figure 6c). The cone appears to be significantly steeper than East Mareotis Tholus or the low shields in Tharsis and Elysium. It is breached on the west, but there are no obvious lava flows emanating from the cone. Neither are there lobate flows on the leeward (eastern) side of the cone that appears to be relatively clean, suggesting that this feature is not a perched lava lake with overflows. Interestingly, the rim is overhung in many locations and able to support a layer of eolian material, which has been measured as at least $4 \mathrm{~m}$ thick in the HiRISE image. This confirms the prediction from thermal inertia and radar measurements that there is a substantial layer of eolian dust on the flanks of the volcano [e.g., Christensen, 1986]. It appears that the 
shape of the cone has funneled winds through the breach such that some parts of the walls are quite clean. These sections of the wall exhibit a series of hard layers with less resistant interleaved material. Overall, these observed characteristics are consistent with a cinder cone with many layers of welded spatter, which are common on Earth [e.g., Wood, 1979; Carr and Greeley, 1980].

[31] There is good physical reason to expect a small cinder cone to have significant welding, while a much
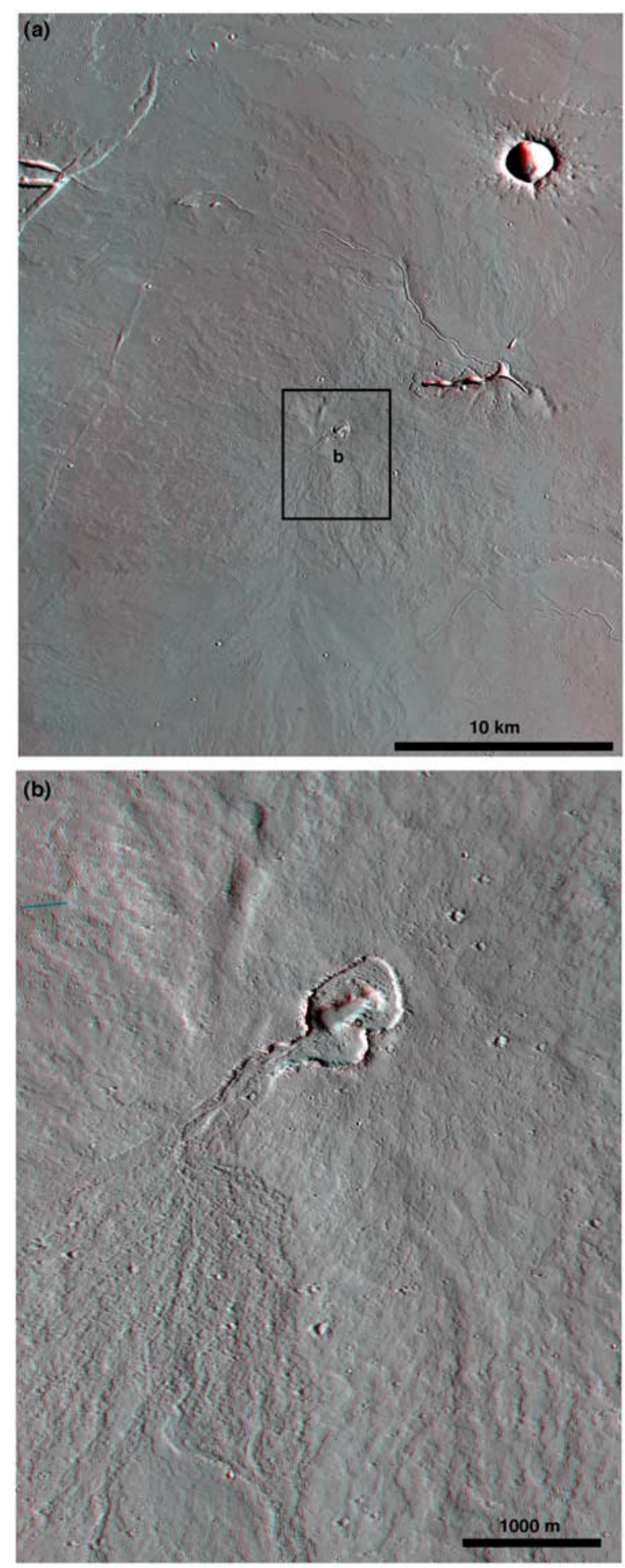

larger pyroclastic construct (e.g., East Mareotis Tholus) might not. To throw pyroclasts kilometers from the vent, the larger cone would require a very vigorous, gas-rich fountain. The lava in such a fountain would be dispersed into small droplets and cool extensively during the long flight time. A less energetic eruption would produce larger pieces of liquid lava that would travel a short distance and remain hot enough to weld upon landing.

\section{Major Shield Volcanoes}

[32] We are finding that HiRISE is not the ideal instrument to study the major volcanic edifices because mantling deposits often obscure the meter-scale volcanic features. Figure 7 highlights the somewhat extreme example of Alba Patera. HiRISE has imaged the caldera margin, which is delineated by a shallow stepped scarp. Not only the volcanic features, but also impact craters appear degraded. The primary culprit is the midlatitude mantling deposit that shows many hints of cryogenic activity [Mustard et al., 2001]. At least the upper few meters in this area is composed of this geologically young unit. It is likely that the shallow rim of the caldera is a primary feature, rather than the result of extensive sedimentary infilling, but we cannot be certain from the HiRISE images alone.

[33] An image from within the caldera of Arsia Mons (Figure 8a) provides a more (volcanologically) interesting case. On the west is an elongated depression with lava flows extending radially away. This is interpreted to be a low shield fed from a short fissure segment, much like the features discussed in the previous section. In this case, neither lava lakes, spatter deposits, nor lava channels are identifiable. The shield is embayed by a series of smooth sheet flows that enter the image from the east. In the northeast, the younger flow exhibits a crenulated ridge that is difficult to interpret. The broader ridges in the east central part of the image are morphologically similar to inflation plateaus [Hon et al., 1994; Keszthelyi et al., 2000].

[34] However, all these features can be discerned in images with a spatial sampling of a few meters per pixel. Attempts to improve the interpretations by examining meter-scale features are frustrated by the mantling deposit. HiRISE reveals that in this location the mantling deposit has a surface characterized by a network of small ridges.

Figure 5. Small vents on the Tharsis volcanic rise. (a) Anaglyph from CTX images P03_002328_2078 and P04_002605_2078. Box outlines the area seen in the corresponding HiRISE anaglyph. Note the variety of different types of flows and channels sourced from diverse depressions. All the flows and channels are interpreted to be volcanic in origin. (b) Cutout of anaglyph from HiRISE observations PSP 002605 2080 and PSP 002328 2080. Centered at $27.5 \overline{6} 1^{\circ} \mathrm{N}, 24 \overline{6} .849^{\circ} \mathrm{E}$. The central feature is interpreted as a perched lava lake. A breach of the lake's levees resulted in the lava fan on the SW side of the edifice. The blurred and etched appearance of the surface is caused by a wind eroded mantling deposit that is at least locally a few meters thick. This obscures all meter-scale volcanic features. 

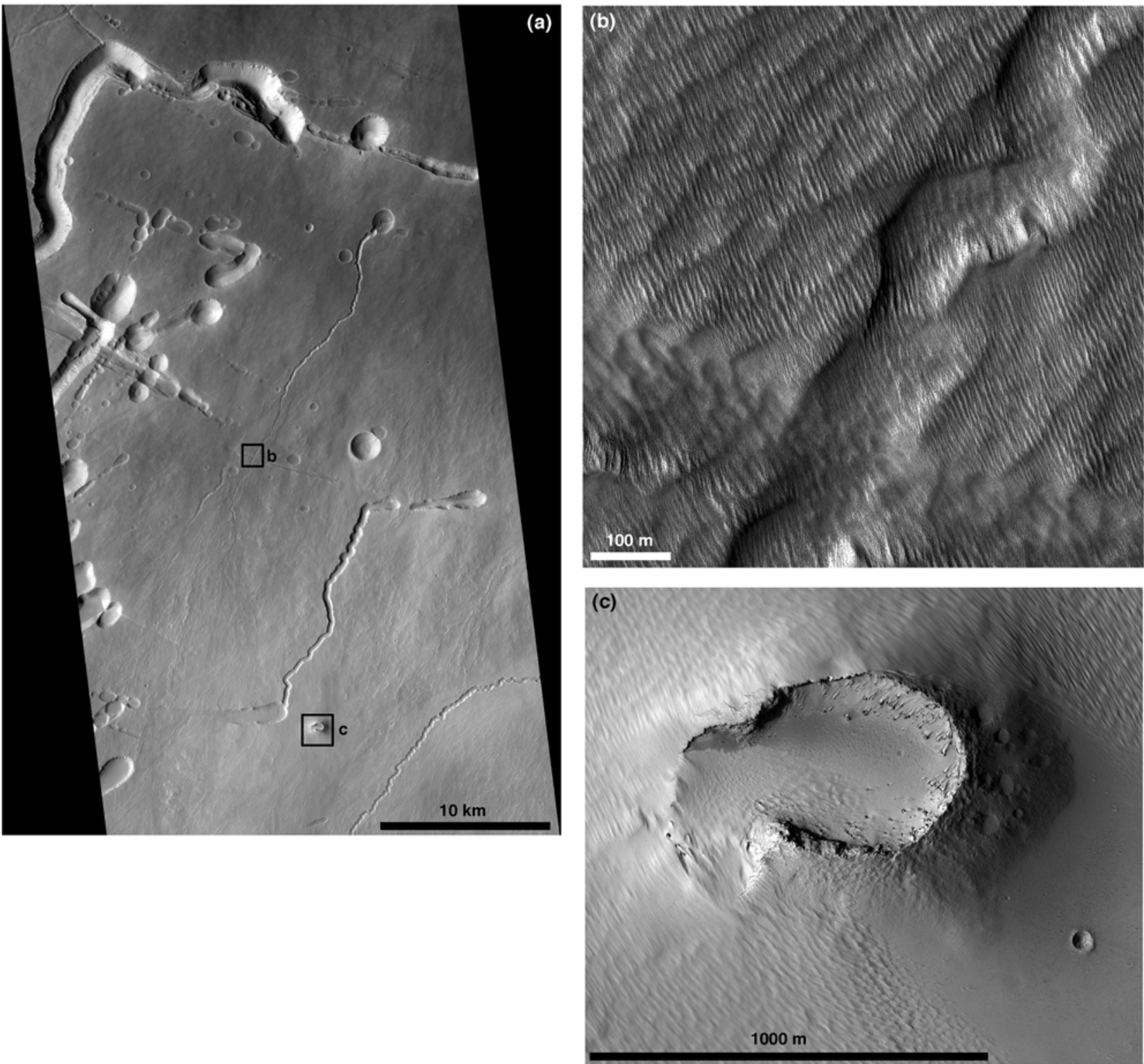

Figure 6. Small vents on the southern flank of Pavonis Mons. (a) Overview from CTX image P04 002671 1792. (b) HiRISE sample of sinuous rille and lava fan. Cutout from image PSP $002671-1790$ centered at $0.822^{\circ} \mathrm{S}, 246.529^{\circ} \mathrm{E}$. Cutout also captures a graben running perpendicular to the lava flows. The entire scene is covered by eolian dune forms which obscure any volcanic and tectonic features at the meter scale. (c) Small cone. Cutout from HiRISE image PSP_002671_1790 centered at $1.092^{\circ} \mathrm{S}, 246.591^{\circ} \mathrm{E}$. The lack of visible lava flow lobes, even on the relatively clean eastern side of this cone, suggests that this is not the source of effusive lava. Instead, the resistant layers seen in the cone's interior walls may be welded spatter.

Conversely, it can be looked upon as closely packed, shallow scallops. The presence of rocky outcrops in the rims of impact craters suggests that the mantle is locally only about a meter thick. A 35-m-diameter irregular crater near the southern end of the image has excavated dark material, again suggesting a relatively thin mantle. If the mantling deposit is uniformly this thin, it would imply that the craters are being erased by some process other than infilling. Of course, mantle deposition could be concentrated within depressions.
[35] It is noteworthy that this scalloped/ridged mantling deposit is both widespread and enigmatic. It is seen across many parts of the Tharsis volcanoes, draping the steep walls of Valles Marineris (e.g., PSP_002354_1680 and PSP_003277_1700), in the equatorial lowlands (e.g., Figure 12), and other locations. One interpretation of the network of ridges is that they are related to star dunes, which form when the winds have multiple preferred directions [Lancaster, 1989]. However, many observations do not fit a dune hypothesis and it is possible that these are actually erosional features in a weakly indurated, fine-grained 

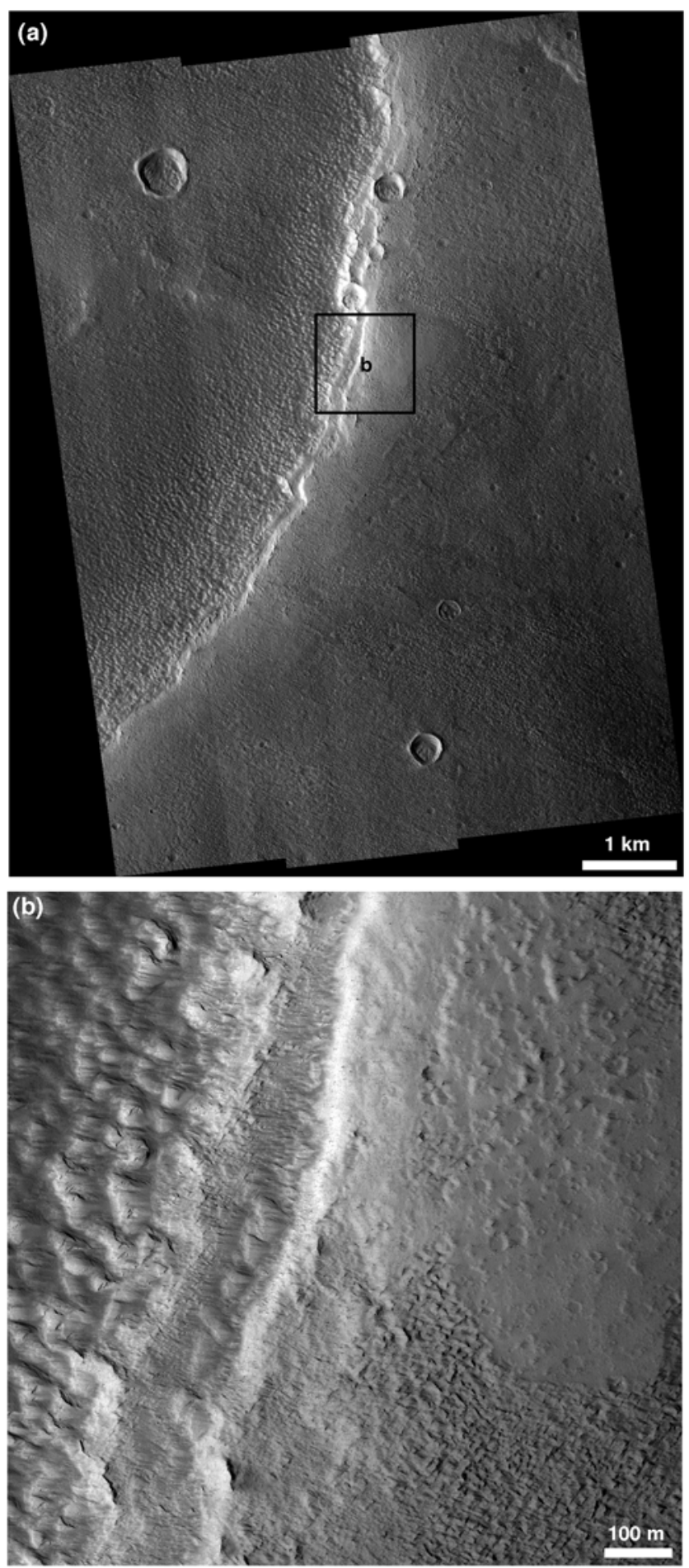

Figure 7. Alba Patera caldera rim. (a) HiRISE image PSP 001510 2195. Box shows the location of the close-up. Note the extensive modification of the impact craters and the absence of recognizable volcanic features other than the shallow rim of the caldera. (b) Close-up centered at $39.351^{\circ} \mathrm{N}, 251.543^{\circ} \mathrm{E}$. The caldera fill material (on the west) appears to be shaped by eolian erosion. The mantling deposit above the rim varies from smooth to rough. It is likely that the rough texture is the result of degradation of the smooth mantling unit, perhaps by sublimation of trapped volatiles (i.e., ice).
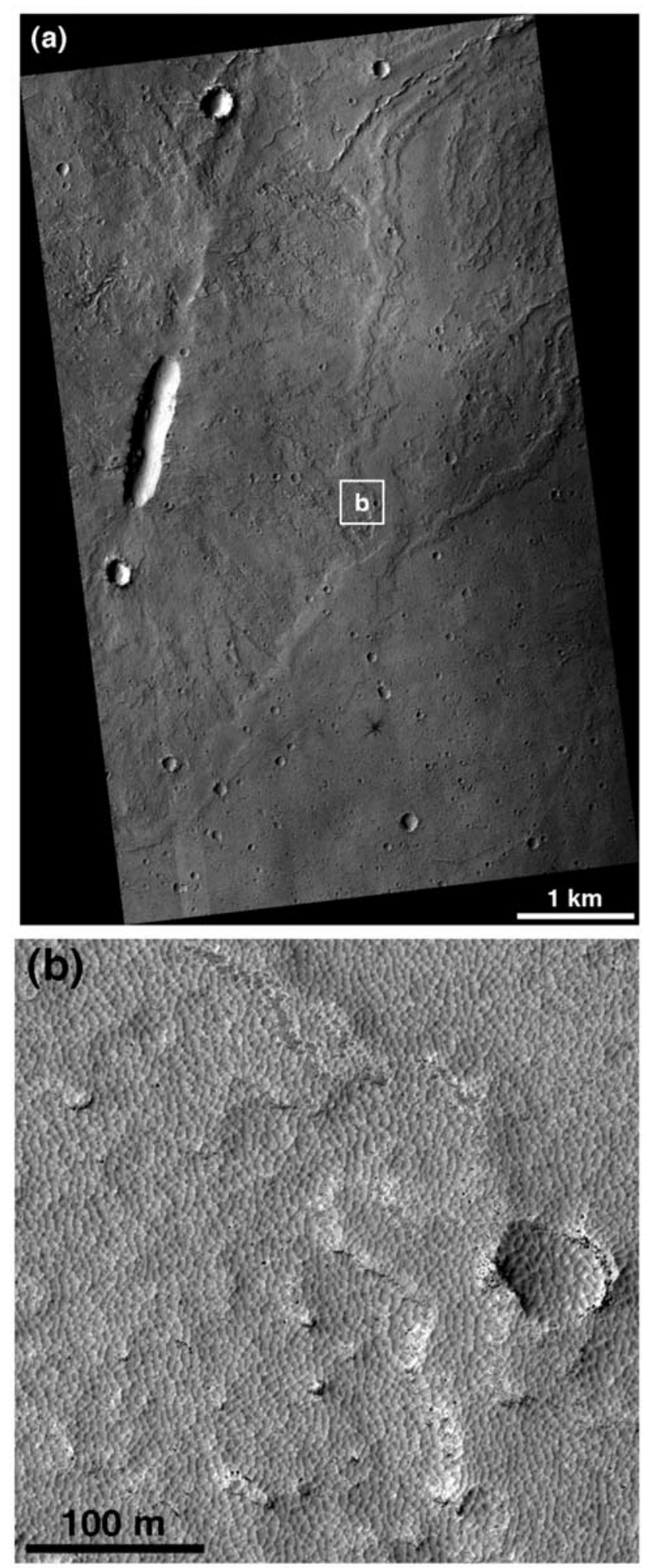

Figure 8. Floor of Arsia Mons caldera. (a) HiRISE image PSP_002157_1715. Elongate depression on the west is a low shield, partially embayed by lava flows from the northeast. Dark "spider-like" feature in the south central part of the image is a recent impact crater whose ejecta has disturbed the bright eolian deposits. (b) Close-up centered at $8.451^{\circ} \mathrm{S}, 240.146^{\circ} \mathrm{E}$. No additional details about the lava flow contacts can be discerned because of the eolian cover. The origin of the small scallops/ridges is enigmatic. 

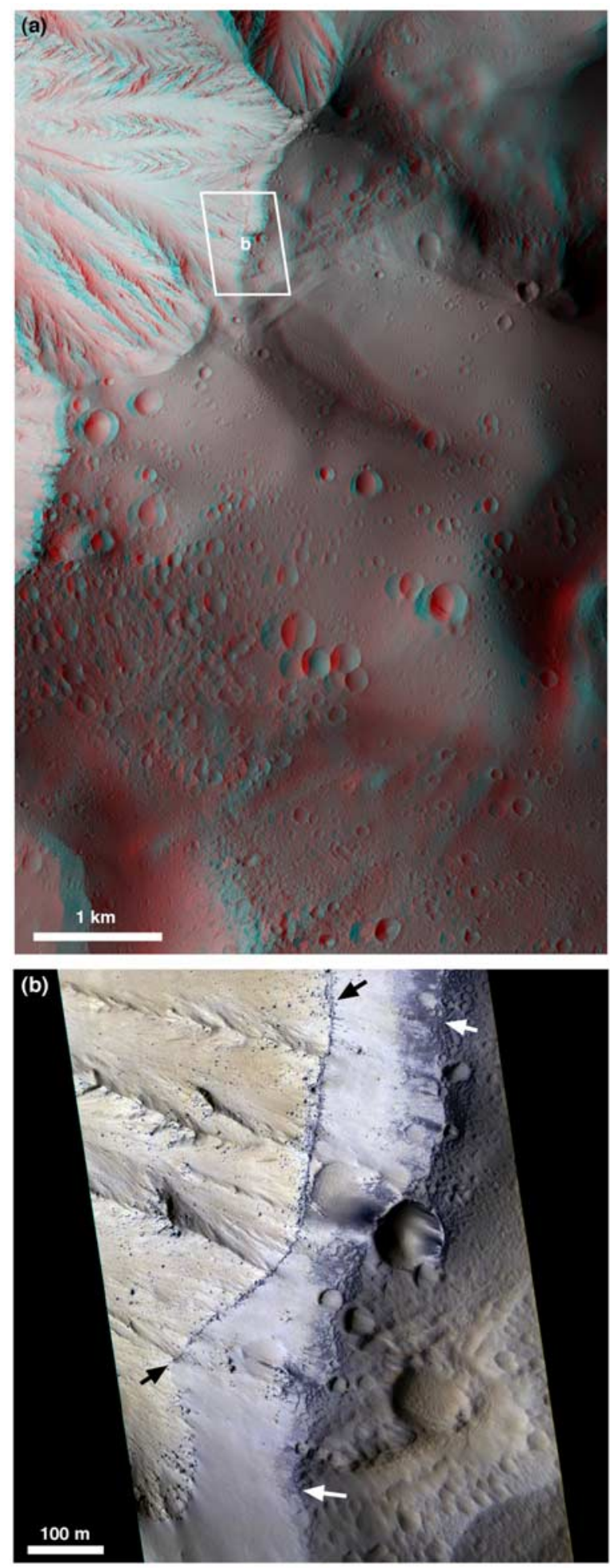

Figure 9. Western flank of Olympus Mons. (a) Sample of anaglyph produced from HiRISE observations PSP 0014322015 and PSP 0016302015 , centered at $21.583^{\circ} \mathrm{N}, 222.306^{\circ} \mathrm{E}$. (b) False color close-up centered at $21.500^{\circ} \mathrm{N}, 222.354^{\circ} \mathrm{E}$ from PSP_001432_2015. Note that the upper portion of the scarp above the thin resistant layer is more whitish (in false color) than either the lower section of the scarp or the surface of the volcano. Black arrows indicate the boulder-rich layer and white arrows show the top of the scarp. material. These enigmatic landforms are being studied by the HiRISE team and is reported on by Bridges et al. [2007].

[36] In order to study meter-scale volcanic features on the major edifices it is necessary to find locations where the mantle is either removed or thin. We have therefore emphasized imaging steep topography formed relatively recently. This includes the interiors of young impact craters, caldera walls, collapse pits, and landslide head scarps. The sites imaged to date do provide cross-sectional views into the volcanoes, but we have not yet found an outcrop clean enough to provide substantial new insight.

[37] Figure 9 shows a section of the western edge of the Olympus Mons basal scarp. On a kilometer-scale, this part of the volcano is disrupted into large blocks (Figure 9a). Within this image, the highest topography is along the margin of the scarp. This is suggestive of the flank of the volcano having been over-steepened by compression, then suffering from large-scale mass wasting. This observation is consistent with the idea that Olympus Mons is exhibiting many symptoms of gravitational collapse [e.g., McGovern et al., 2006].

[38] Perhaps because of this tectonic disruption, the volcanic stratigraphy is not clearly expressed in the face of the scarp. Substantial outcrops of hard rock can be seen, but layering is difficult to discern. It is plausible that these rocks have been brought up from deep within the volcano and are either metamorphic or intrusive rocks. However, the eolian mantling deposit is thick enough to obscure thin bedding. The only clear layering is at the very top of the scarp (Figure 9b). The lower hard rocks are capped by a thin, almost continuous, outcropping of boulders. This does not appear to be a distinct stratigraphic unit (such as an individual lava flow) associated with the hard rocks underneath. Instead, it appears that mass wasting and erosional processes have combined to preferentially expose the top of the rocky material.

[39] Above the line of boulders lies a distinct unit with very few boulders. In fact, all the boulders in this upper unit are likely to be impact ejecta. The unit retains a similar thickness over rugged topography. This indicates that the unit was either deposited before the region was tectonically disrupted or that it formed in a manner that does not follow the Principle of Original Horizontality [Steno, 1669]. The exposures of this unit are between 100 and $200 \mathrm{~m}$ in lateral extent when viewed from above. The stereo data (Figure 9a) suggest that this variation corresponds to changes in the slope of the exposure with the larger extents corresponding to lower slopes. The unit has a roughly constant thickness of about $60 \mathrm{~m}$ and forms slopes of $15^{\circ}-30^{\circ}$. In cross section, this upper unit also appears to have a different color than the mantled rocky material underneath. Interestingly, the top surface of the upper unit has a similar (yellowish) HiRISE false color as the dust-covered rocks below. This suggests that (1) the boulder-poor unit is not simply an accumulation of the eolian cover, (2) a thin eolian mantling deposit is found both on the rocky parts of the basal scarp and on the flanks of the volcano, and (3) this eolian deposit is not found on slopes formed in the boulder-poor layer. Our favored hypothesis at this time is that the upper unit is a volcanic air fall deposit. This would explain the lack of boulders and the uniform layer thickness over variable topography. If poorly indurated, slopes in the 

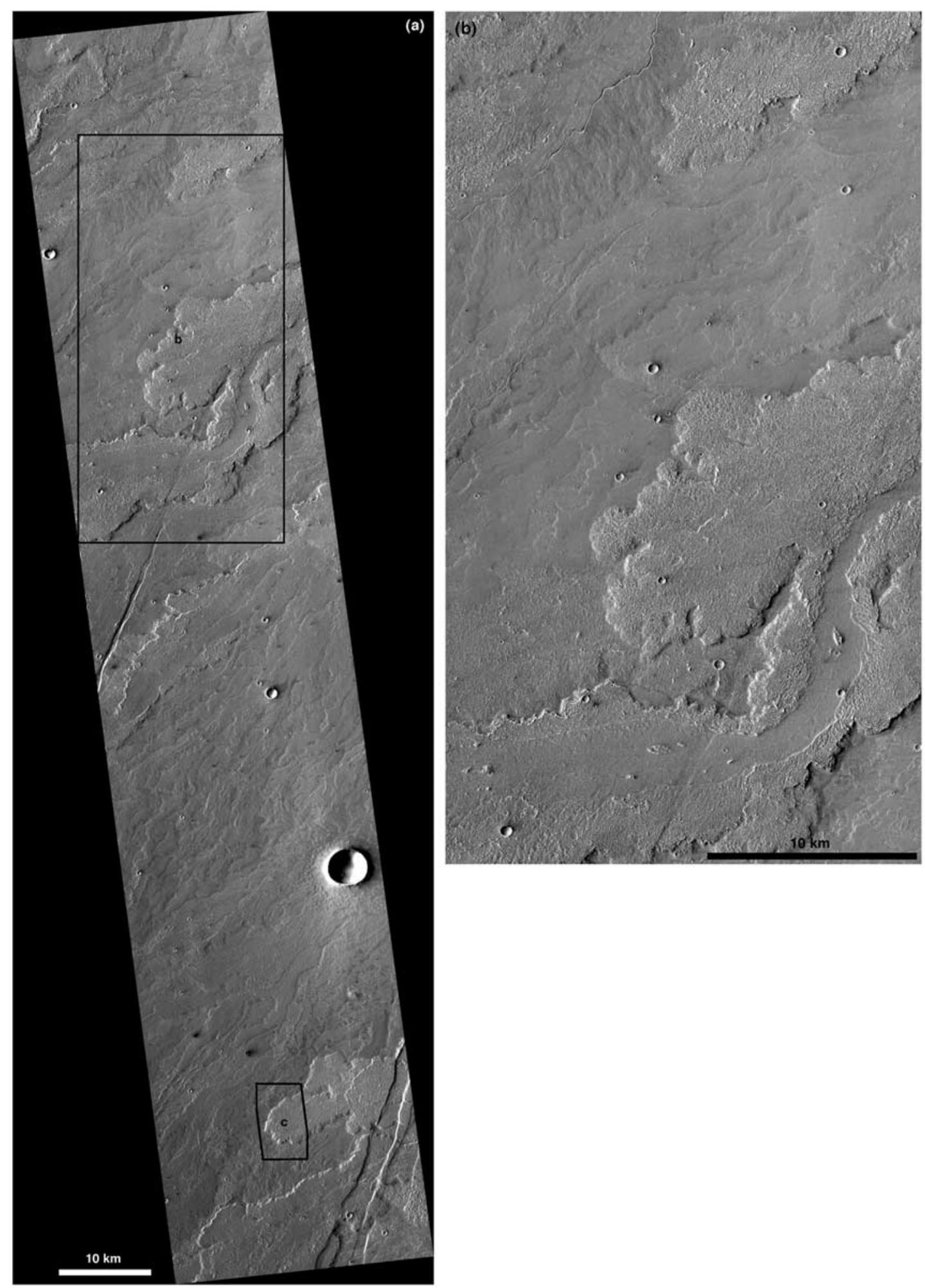

Figure 10. Lava flows of Daedalia Planum. (a) Overview provided by CTX image P04_002711_1560. Note the diversity of channelized lava flows and the crosscutting relations with graben. (b) Close-up of CTX image centered at $21.92^{\circ} \mathrm{S}, 236.51^{\circ} \mathrm{E}$ showing two extremes in the morphologies of channel-fed lava flows. Note the narrow channel with many overflows to the north and the wide channel with streamlined islands in the south. Also note the subtle expression on the surface of the lava flow of the graben that the southern lava flow buried. (c) Portion of HiRISE observation PSP_002711_1550 showing the "ridged" brecciated flow top of a thick lava lobe. (d) Close-up of lobe surface in false color. The flow is largely covered by fine-grained eolian material, but boulders do crop out. 


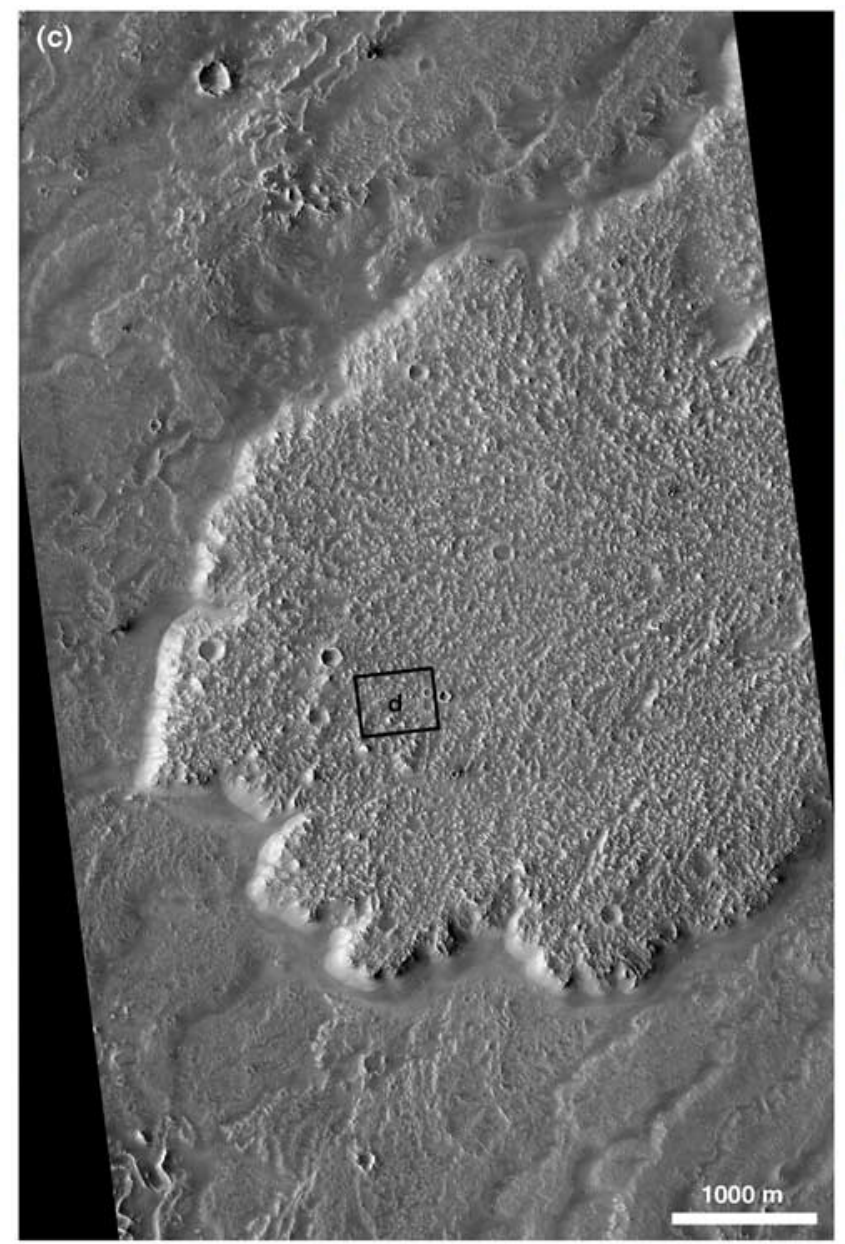

Figure 10.

ash would be easily eroded, preventing eolian deposits from accumulating. Since the bottom of an air fall deposit is rarely welded, this hypothesis suggests that the line of boulders separating the mantling layer from the underlying rocks is primarily an erosional feature. Parts of the basal scarp are covered by younger lava flows, so Olympus Mons should have been active since the formation of the scarp seen in Figure 9. Since this area was locally uplifted by faulting, lava flows did not cover this section of the scarp. However, pyroclastic materials that should have accompanied the eruptions that fed the young lava flows could have accumulated here. While the evidence is not conclusive at this point, it appears that much of the thick cover on the major edifices may be volcanic ash rather than dust deposits from global dust storms.

\section{Flood Lavas}

[40] Flood lava flows cover a large fraction of the surface of Mars [e.g., Keszthelyi and McEwen, 2007] and the new MRO data helps detail their morphologic diversity. There are numerous lava flows $\sim 1000 \mathrm{~km}$ long that extend across the plains away from the major volcanic edifices. These flows appear to be transitional between classic flood lavas that completely inundate an area and shield-building lavas. Figure 10 shows a variety of lava flows in Daedalia Planum.

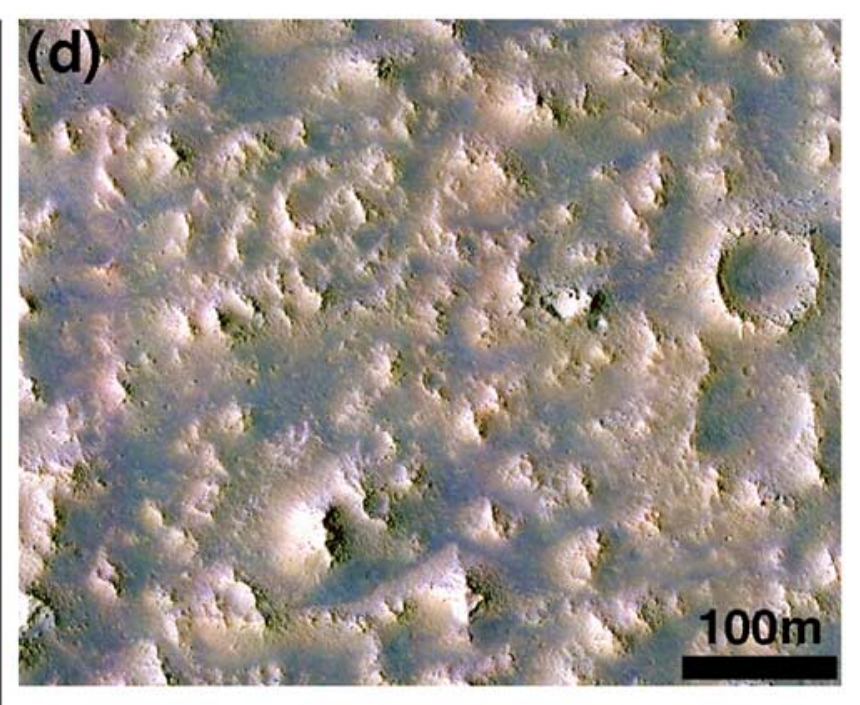

(continued)

Many of the larger lava flows in this area can be traced back to (or toward) the lava apron abutting the southern flank of Arsia Mons. The northwestern part of Figure 10b shows a flow fed by a narrow ( $\sim 50 \mathrm{~m}$ wide) channel. The lava flow surface consists of thousands of individual spillovers from the channel. Each of these spillovers would be considered a significant lava flow on Earth, ranging from 2 to $7 \mathrm{~km}$ in length and hundreds of meters in width. The channel is clearly constructional, as it now sits atop a local topographic ridge. This compound channelized flow embays a similar flow to the south, albeit with fewer and larger spillovers. The southern half of Figure 10b is dominated by a large channelized flow with tall lobate margins. The central channel ranges in width from 0.9 to $3.2 \mathrm{~km}$ and preserves streamlined islands up to a kilometer in length. The surface of the channel levees and flow lobes is covered with an intensely knobby or "ridged" texture.

[41] Details of this ridged flow top can be seen in HiRISE image PSP_002711_1550 (Figure 10c). Overall, the morphology of the flow surface appears remarkably similar to that of terrestrial lava flows with brecciated tops (e.g., aa, rubbly pahoehoe, and blocky flows). However, the scale of the brecciation is unlike that which is commonly seen in aa flows. The hummocks in this Martian example are many tens of meters in size while similar features are usually only a few meters in size on terrestrial aa flows. Instead, the 
rubbly pahoehoe crust on large Icelandic lava flows is most similar in terms of both morphology and scale [Keszthelyi et al., 2004]. Details of the flow top are unfortunately obscured by a fine-grained mantle (Figure 10d).

[42] An interesting note is that the emplacement of these lava flows was contemporaneous with major tectonic activity. Graben clearly cut some lava flows (e.g., at the southern end of Figure 10a). However, the graben in Figure $10 \mathrm{~b}$ is overrun by lava. The trace of the graben that can be seen in the flow could be evidence for minor reactivation of the faults after the lava flow was emplaced. An alternative possibility is that these features formed as the lava interacted with the preexisting topographic depression. The shallow depression in the southern part of Figure 10b might have formed as a small amount of liquid lava drained into subterranean recesses after the flow had been emplaced and largely solidified. There is also a slight disruption of the lava on the eastern edge of Figure 10b, along what could be a buried en echelon extension of the visible graben.

[43] Another example of a "ridged" flow can be seen in Marte Vallis (Figure 11). Like any fluid, lava follows the local topographic gradient, so it is not surprising that we find lava flows inside many outflow channel systems on Mars. What is somewhat uncanny is how well the flow appears to fit the carrying capacity of this channel, filling it from rim to rim, but missing some of the side channels (Figure 11a). This lava flow was examined using the earlier MOC image SP2-40703 and MOLA topography [Keszthelyi et al., 2000], but HiRISE observation PSP 0020271980 (Figure 11b) reveals new details. The central, smoother and thus lighter-toned part of the flow appears to be a broad channel in which flow was concentrated between distinct shear zones. The dark flow-parallel lineations within this channel seen in MOC are now resolved into wakes cut into the flow top as it translated past a fixed obstacle. At the front of the wake, there is a large mound consisting of broken pieces of the flow top that became stranded on the now buried obstacle (Figure 11c). A series of narrow ridges can be seen running roughly perpendicular to the flow direction indicated by the wakes. These consist of large boulders and are interpreted to form as pressure ridges where the crust failed in compression. The margins of the channel exhibit tension gashes that formed by the shearing induced by the large differential in flow velocity at the channel margins.

[44] Away from this broad channel, the crust largely consists of an extremely rough surface that forms irregular ridges and hummocks. Detailed examination of the HiRISE image shows that there is a continuum from pressure ridges to closely packed irregular ridges to a jumble of large bouldery hummocks identical to the surface in the Daedalia Planum flow (Figure 10c). This confirms the suggestion of Keszthelyi et al. [2004] that the ridged flow tops form by an extended period of brecciation during the emplacement of the lava flow. This rough surface is locally rafted apart with a relatively smooth surface filling the rifts. Small shear zones can often be recognized bounding the pieces of crust that moved apart. The result is a patchwork of irregular, deformed plates $0.1-1 \mathrm{~km}$ in size. It is this combination of ridged crust and rafted plates that led Keszthelyi et al. [2000] to describe these types of flows as "platy-ridged" lava flows. Comparison to terrestrial analogs has shown that platy-ridged lava flows are synonymous with the rubbly pahoehoe flows found in terrestrial flood basalt provinces and Iceland [Keszthelyi et al., 2004].

[45] The distal margin of the lava flow is extremely crenulated, being composed of a mass of intertwined small digitate lobes. This texture is common for large pahoehoe lava flows, but the dust cover is thick enough to obscure the details of these small lobes. It is noteworthy that the parts of the rubbly pahoehoe flows in Iceland that exhibit a similar platy-ridged surface also transition to pahoehoe lobes at the outer margins [Keszthelyi et al., 2004].

[46] The light and dark bands along the western edge of Figure 11b (highlighted with arrows) are of particular interest. These bands are the result of topographic ridges and troughs that line the banks of the main channel. Similar (but larger) features are seen in the upper reaches of Athabasca Valles. We interpret this texture as forming as the still partly ductile crust of a lava flow was pulled apart after being draped onto the channel margin. This produces motion toward the center of the channel (presumably during draining and deflation of the flow), which explains the orientation of the rifting. Because it is substantially more cratered than the dark lava flow in the center of the channel, this banded surface must be indicative of a substantially earlier lava flow. In the CTX image (Figure 11a), the extent of this older lava flow can be seen as the transition from a smooth light toned surface to the rougher, yet more cratered, material that the channel was carved into. Partly degraded plates, ridges, and shear zones show that this older lava flow filled Marte Vallis to overflowing. However, before freezing it drained out, leaving the topographic channel that the younger dark lava flow filled. Unless this older lava flow carved Marte Vallis, crater counts of the valley floor will date this lava flow, not the formation of the channel system [cf. Burr et al., 2002]. This observation also means that most, if not all, of the features interpreted to be flood carved are now draped by a thin layer of lava. Other HiRISE observations show that Kasei Valles and Athabasca Valles also are draped with lava [e.g., Jaeger et al., 2007].

[47] Perhaps the most visually spectacular example of platy-ridged flood lavas can be found in Cerberus Palus, the basin in Elysium Planitia at the terminus of Athabasca Valles (Figure 12). This flow was fed by the same strand of the Cerberus Fossae as was shown in Figure 3. Because the lavas are traversing a smooth plain with obstructions nearly $250 \mathrm{~km}$ apart, the plates are able to reach dimensions of order $10 \mathrm{~km}$ (Figure 12a). Similar scale plates can be found in other flat plains, such as parts of Amazonis Planitia and Echus Chasma [Keszthelyi et al., 2000; Chapman et al., 2007]. While the plates are necessarily smaller within the confines of a preexisting channel, all the features seen in the Marte Vallis flow can be found here. However, since the mantling deposit is much thinner in Cerberus Palus, additional details can be discerned in this location (Figure 12b).

[48] At lower resolution, or when covered by a thick mantling layer, the plates appear smooth. However, HiRISE reveals that the plates consist of broken pieces of lava crust, including slabs many meters across (Figures 12c and 12d). It is unclear if this breccia formed as surges in the flow disrupted a smooth crust or if the brecciation was a continual process atop a turbulent flood of lava. However, this lava flow was fed from the vent partially imaged in 

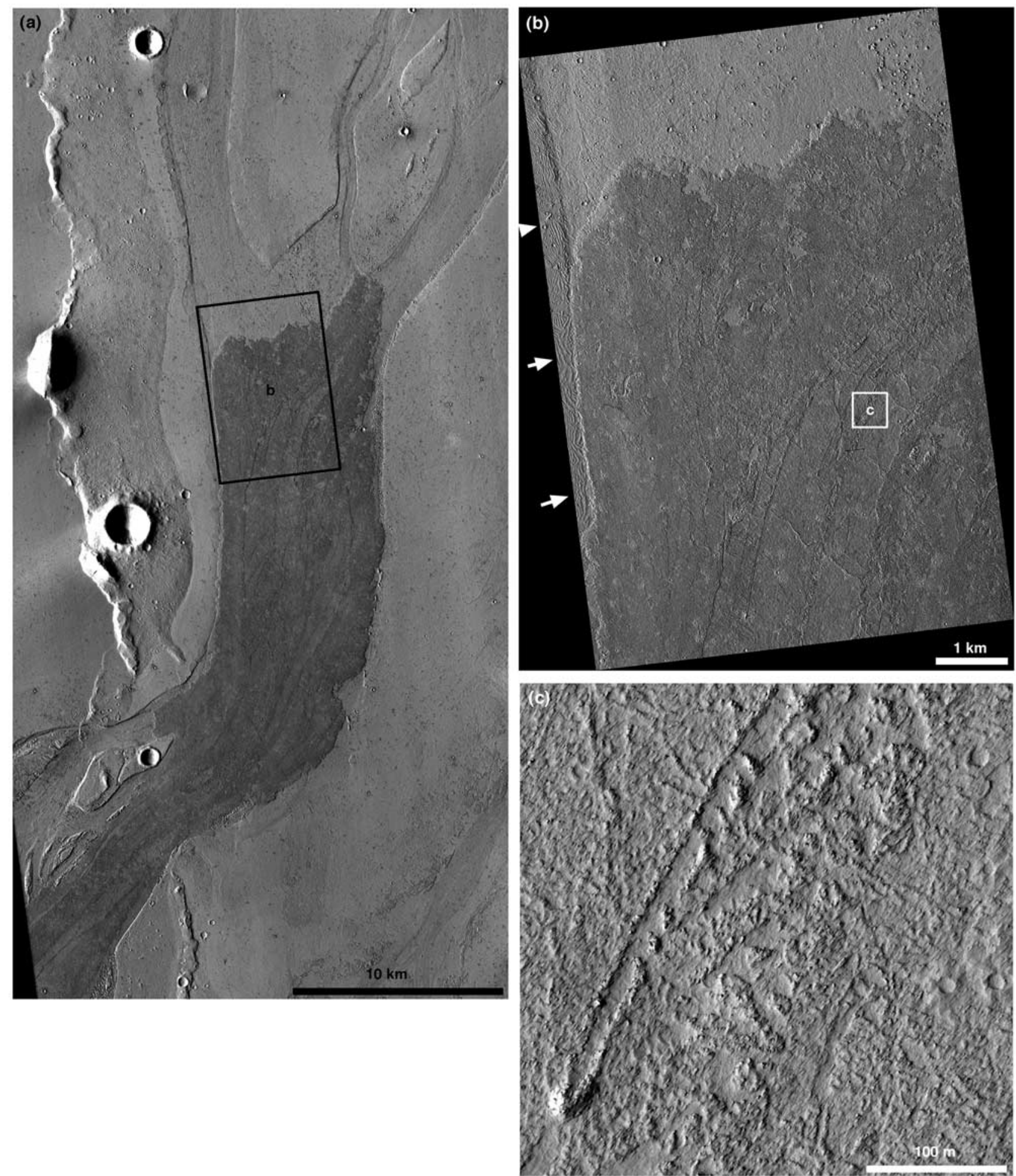

Figure 11. Lava flows in Marte Vallis. (a) CTX image P03_002027_1979, showing the terminus of a flood lava flow within the outflow channel system. (b) HiRISE observation PSP_002027_1980. Parallel curvilinear features in the middle of the image are grooves cut into the top of the lava flow as it translated past obstacles. Note the pressure ridges and the incipient rifting of the crust into kilometer-scale plates. Arrows point to the grooved material on the very western edge of the image. This is the ridged surface of an older lava flow. (c) Close-up centered at $17.694^{\circ} \mathrm{N}, 185.528^{\circ} \mathrm{E}$ showing the accumulation of boulders of flow top material at the front of one of the wakes. Note the wind-sculpted mantling deposit. 

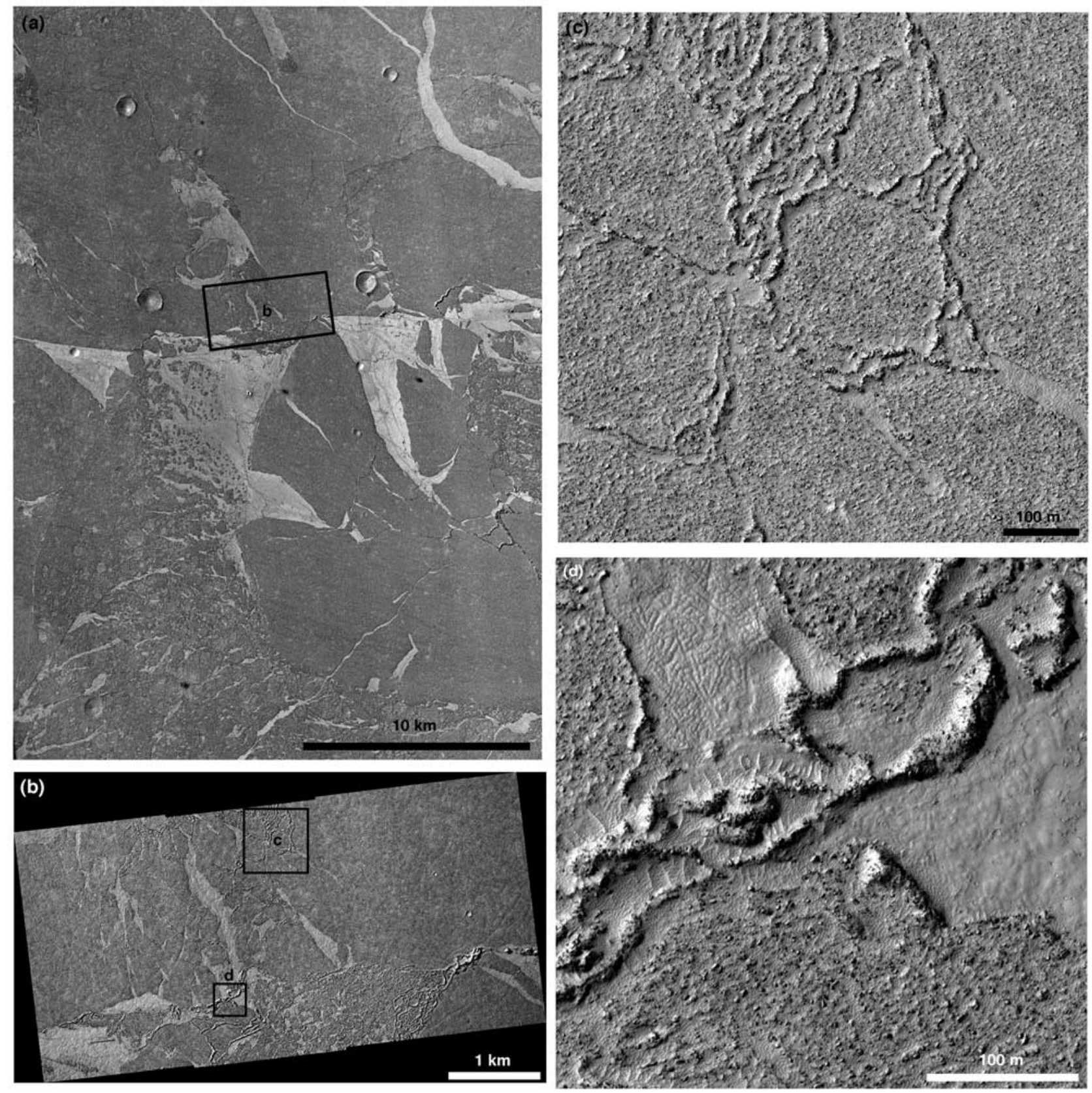

Figure 12. Platy-ridged lava in Cerberus Palus. (a) Sample of CTX image T01_000854_1856 showing rafted plates up to $\sim 10 \mathrm{~km}$ across. (b) HiRISE image TRA_000854_1885. (c) Close-up centered at $5.545^{\circ} \mathrm{N}, 152.153^{\circ} \mathrm{E}$ showing the transition from "flat" to "ridged" flow tops. (d) Close-up centered at $5.516^{\circ} \mathrm{N}, 152.145^{\circ} \mathrm{E}$ showing the smooth "polygonal" surface that forms between rafted plates. Note also that in the center of the image transverse dune forms are superimposed on the scalloped mantling deposit.

Figure 3, where we found direct evidence, in the form of successive overlapping flows, that the flow rate was surging, at least toward the end of the eruption. At the same time, the flux of lava that passed through Athabasca Valles was sufficient to induce turbulence in the lava flow [Jaeger et al., 2007]. It is likely that a combination of unsteady flow and turbulent eddies were involved in disrupting the surface of the flow during peak discharge.

[49] The style of motion that we see preserved in the rafted plates in Cerberus Palus suggests that they formed after the flow rate had been reduced and flow was in the laminar regime. Still, given the inherent complexity of real lava flows, it is evident that the motion was chaotic. For example, we can see several locations in the HiRISE image where the plates show evidence of rafting apart from, and colliding with, their neighbors without a consistent direction of motion (Figures 12a and 12b). Instead, the collisions (and possibly rotations of the plates) have rounded their perimeters (e.g., Figure 12c). The margins of the plates that have suffered collisions are marked by ridges of crumpled crustal 

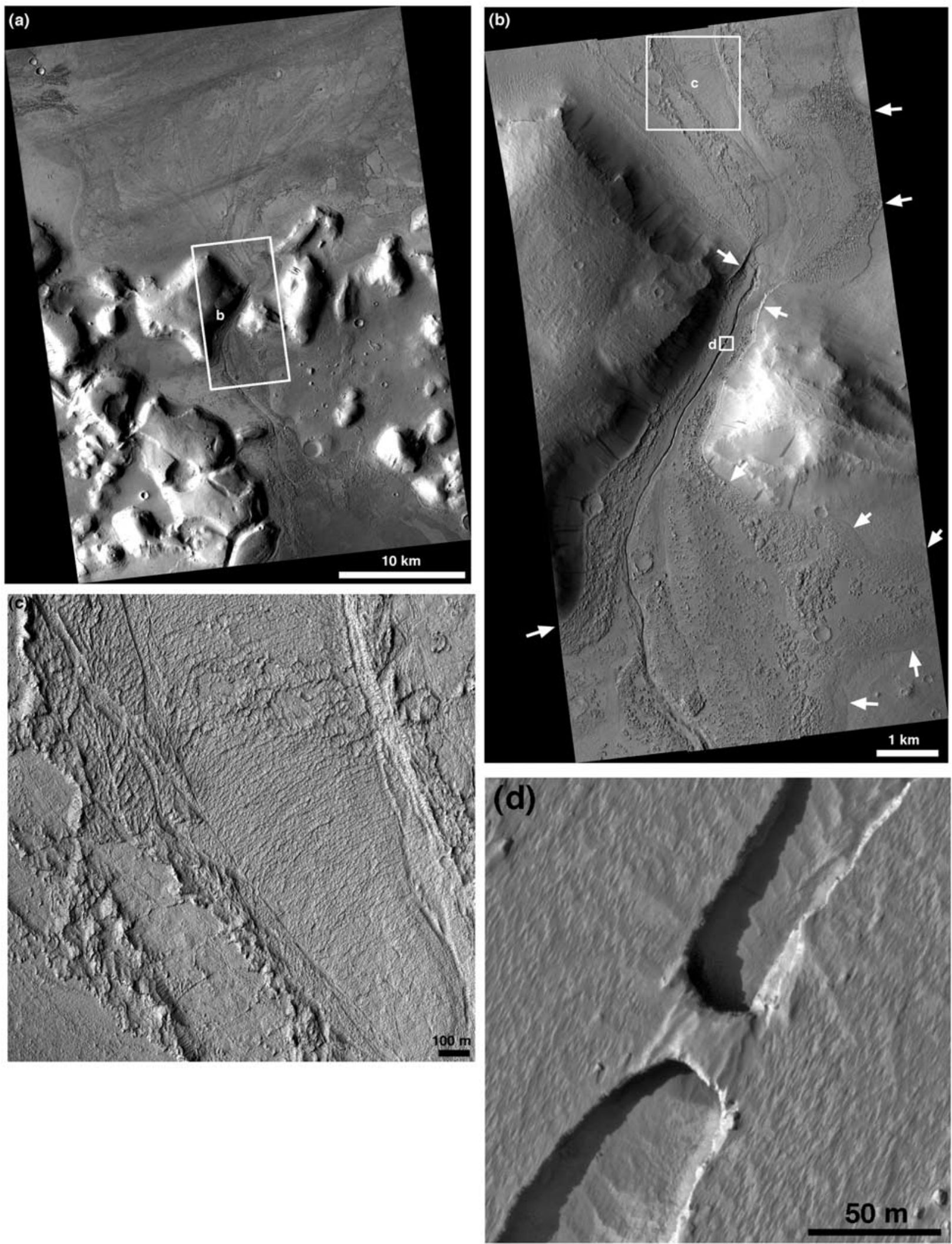

Figure 13. Lava flow winding through the Tartarus Colles. (a) Overview from CTX image P01_001420_2047. The lava flow passed from the south to the north. Note the large plates and ridges on the flow. (b) HiRISE image PSP_001420_2045 of the flow through a constriction between two knobs. Prominent ledge, indicated with the arrows, marks the high lava level. (c) Close-up of the broad lava channel formed in the flow after it passed through the constriction, centered at $24.554^{\circ} \mathrm{N}, 188.125^{\circ} \mathrm{E}$. (d) Close-up of roofed section of the lava channel, centered at $24.484^{\circ} \mathrm{N}, 188.135^{\circ} \mathrm{E}$. 

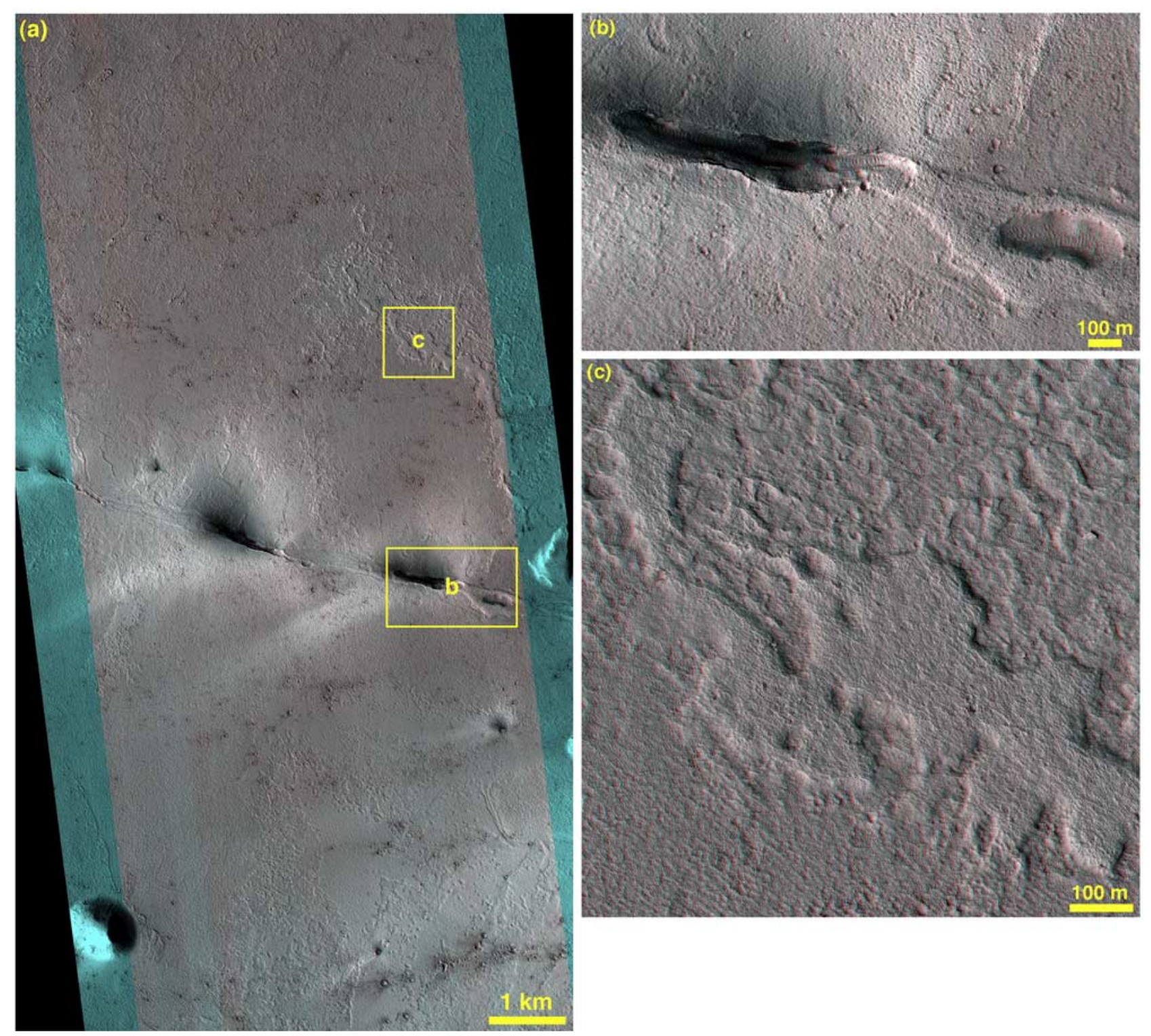

Figure 14. Inflated lava flows in Elysium Planitia. (a) Anaglyph produced from HiRISE observations PSP_003241_1880 and PSP_003531_1880. The diagonal banding is due to imperfect calibration of these hazy images. A segment of the Cerberus Fossae cross the center of the figure, but it is unclear if it was the source of these lavas. (b) Close-up centered at $7.688^{\circ} \mathrm{N}, 164.418^{\circ} \mathrm{E}$ showing collapsed and inflated lava over the fissure. (c) Close-up centered at $7.741^{\circ} \mathrm{N}, 164.410^{\circ} \mathrm{E}$ showing a classic example of an inflation plateau.

material (Figures $12 \mathrm{c}$ and $12 \mathrm{~d}$ ). In some cases, the plates have been completely crushed, reducing them to a series of subparallel ridges. One example of this is highlighted in the northern central part of Figure 12c.

[50] Another piece of evidence that the rafting took place in a relatively quiescent flow regime can be found in the area between the plates. The surface of the lava flow in these areas is composed of polygonal hummocks a few meters across (Figure 12d). The scale and shapes of these hummocks are identical to those found on the surface of lava lakes and other quiescently formed mafic lava surfaces [Keszthelyi et al., 2004]. It is completely different in morphology from the "polygonal terrain" seen in Martian permafrost. However, even the polygonal lava surfaces have been locally brecciated where they have failed in compression to form pressure ridges (Figure 12d).

[51] While in general these giant flood lavas moved as broad sheets, we do find evidence that they locally formed lava tubes when the flow was confined by the surrounding topography (Figure 13). The CTX overview (Figure 13a) shows that this lava flow in the Tartarus Colles has classic platy-ridged morphologies on the flat plains. Some of the plates in the northeastern edge of the CTX image are nearly $5 \mathrm{~km}$ across, approaching the size of the plates in Cerberus Palus (Figure 12). Pressure ridges and shear zones along the margins of channels are also apparent.

[52] However, as the flow moved from south to north in between the hills of the Tartarus Colles, it became restricted 

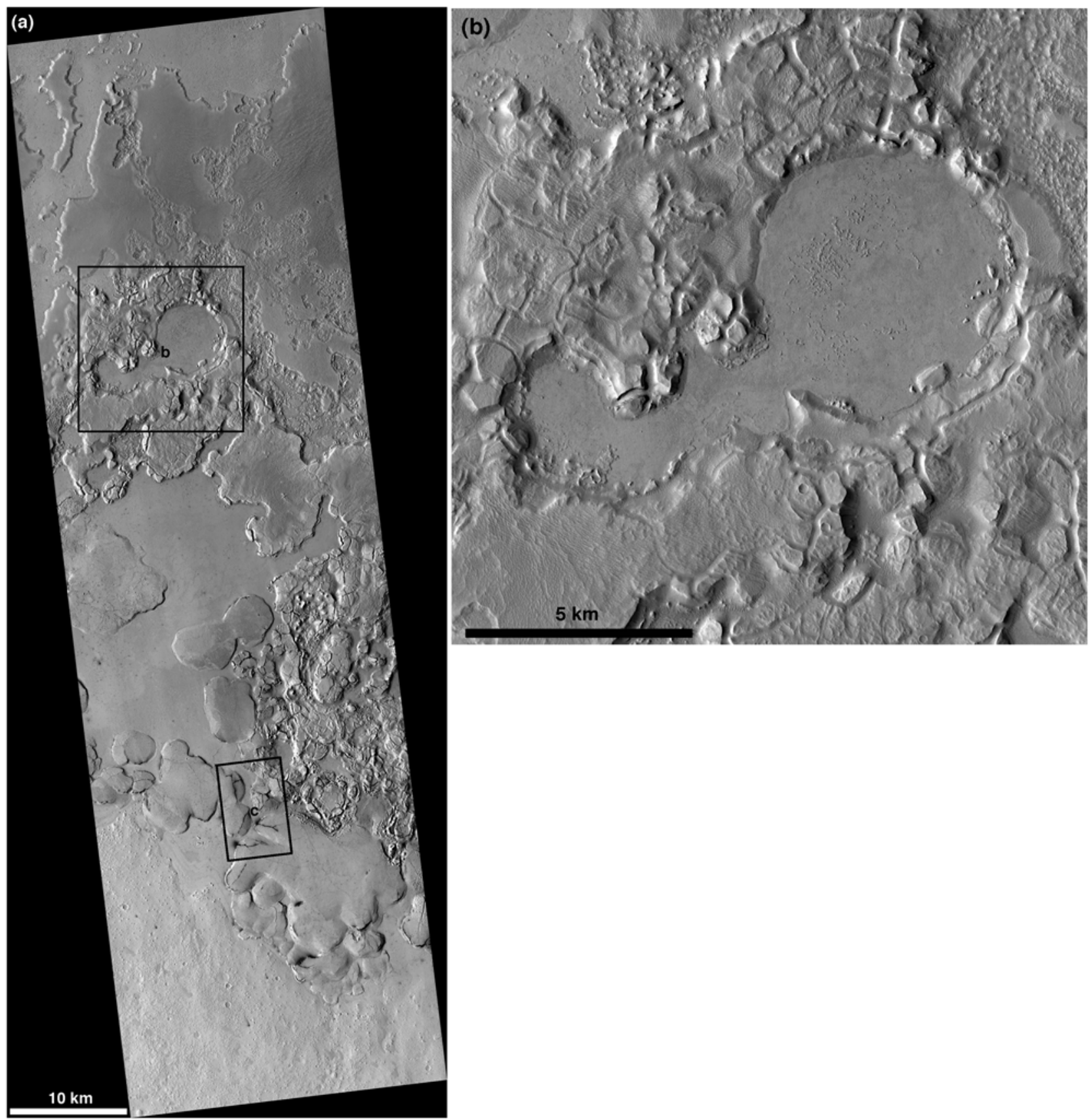

Figure 15. Enigmatic uplifts in southern Elysium Planitia. (a) Regional view from CTX image P04_002542_1772. The region is covered with 10-km-scale uplifted plateaus. While most of the uplifted surface shows a platy-ridged lava morphology, the material in the northeast appears to have a different (weaker) lithology. (b) Close-up showing a fully enclosed basin filled with platy-ridged lava, centered at $1.54^{\circ} \mathrm{S}, 167.34^{\circ} \mathrm{E}$. (c) Overview of HiRISE image PSP_002542_1765. Note the hummocky nonlava material atop the lava uplifts in the northeast corner. This material and its relationship to the lava are discussed in the text. (d) Margin of a multikilometer-scale uplift. Close-up centered at $3.210^{\circ} \mathrm{S}$, $167.881^{\circ} \mathrm{E}$. The uplift appears to be embayed by a later lava. (e) Smaller uplifts on the lava surface with the same morphology and dimensions as typical terrestrial tumuli. Close-up centered at $3.269^{\circ} \mathrm{S}$, $167.928^{\circ} \mathrm{E}$.

to a passage less than $1 \mathrm{~km}$ wide (Figure 13b). While tongues of lava reach between other knobs, no other pathway was available for the flow. As the flow debouched from the narrow pass, it formed a broad central channel within the expanded sheet flow (Figure 13c). The margins of the channel are marked by large shear zones. Outside the channel, the flow surface is largely composed of broken pieces of crust that became stranded as the flow level 

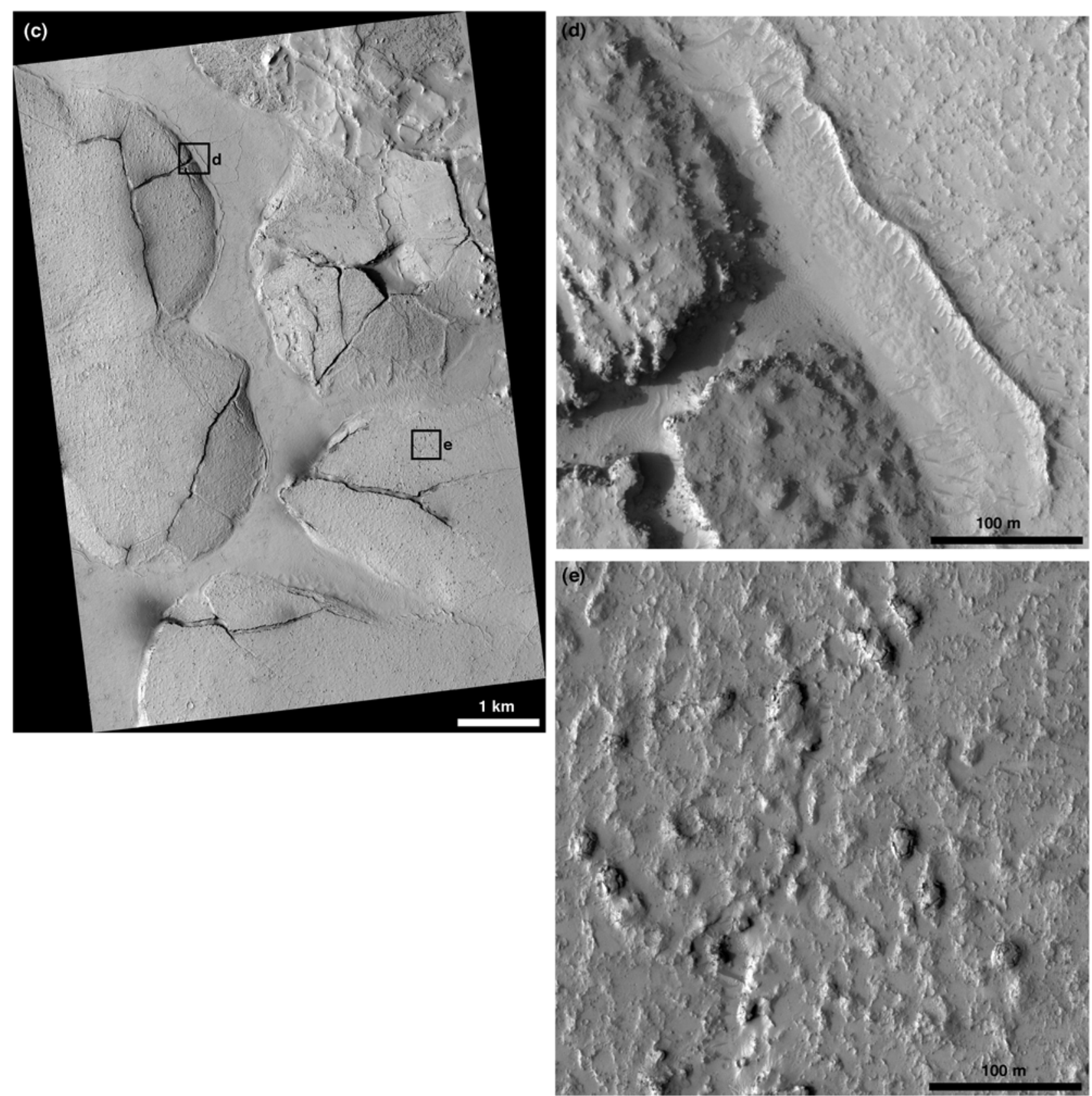

Figure 15. (continued)

receded. Within the channel itself, the lava surface is covered with ridges transverse to the flow direction and convex in the down flow direction (Figure 13c). This suggests that the flow top within the channel was crumpled as the front stopped but the lava within the channel continued to creep forward.

[53] Within the narrows, a sharp ledge appears to mark the high lava stand at peak discharge (Figure 13b). Stranded blocks of crustal material can be found littering the slopes of the valley. A narrow (30-50 m wide, $\sim 20 \mathrm{~m}$ deep) channel runs down the center of the valley. Other than a dearth of identifiable overflows, this channel is similar in morphology to the narrow channels seen in Daedalia Planum (Figure 10b). The smooth transition to the lava flows beyond the valley leaves no doubt that this is a primary volcanic channel.
Interestingly, a short span of the channel has an intact roof, indicating that some portion of this channel functioned as a lava tube. Because the level of this roof is much below the high-lava marks, it must have formed after the lava level (and flux) had dropped substantially. In fact, it is obvious that this channel could not have carried enough lava to form the broad sheet flows to the north. Therefore, this channel must record the very end of waning flow in this area.

[54] Evidence for relatively gentle emplacement of Martian flood lavas can also be seen in other locations. For example, PSP_003241_1880 shows a section of the Cerberus Fossae covered with inflated sheet flows (Figure 14). A particularly well-formed set of amoeboid raised plateaus is highlighted in Figure 14c. The raised surfaces have occasional circular pits whose bottoms remain at the level 

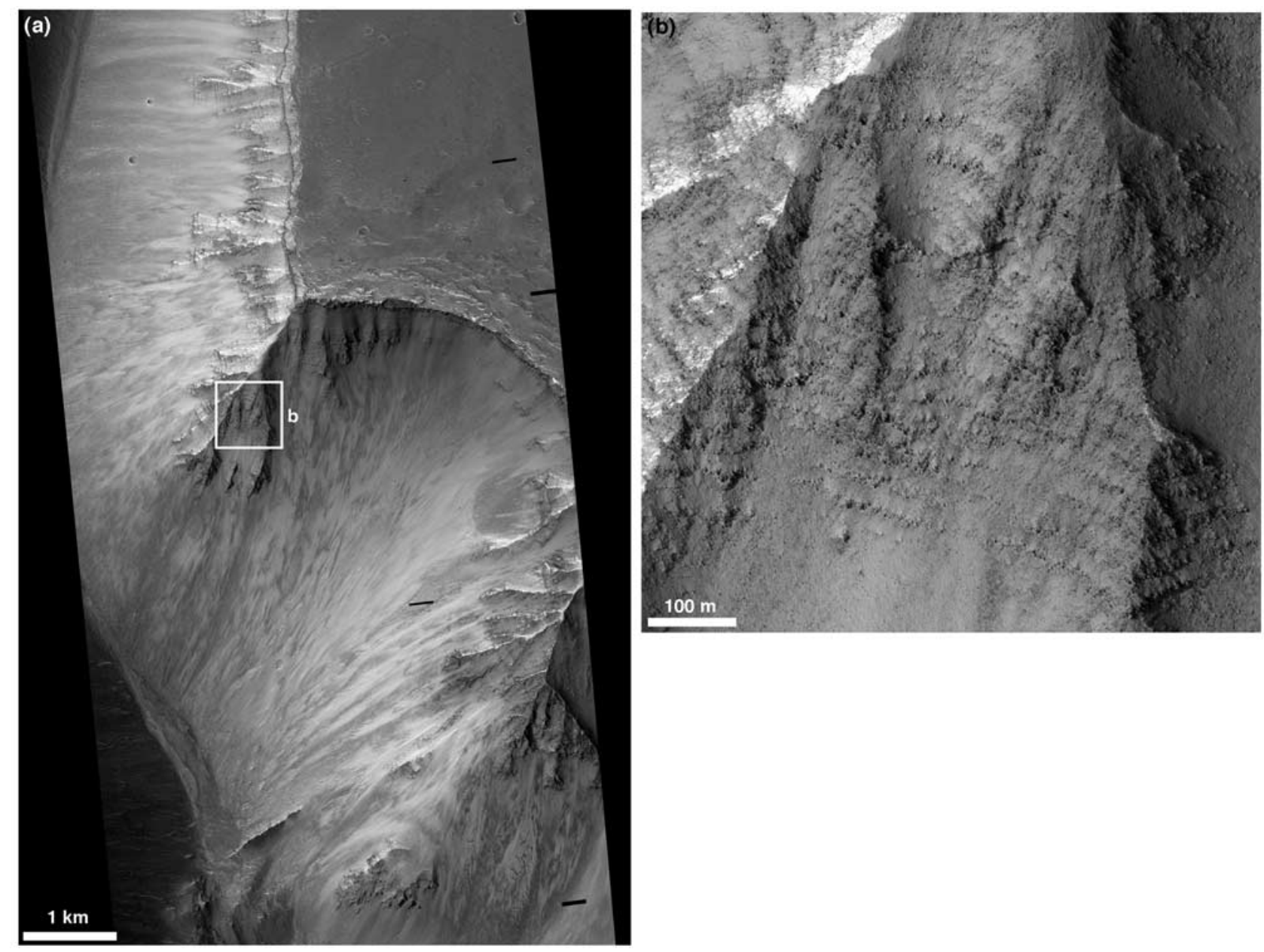

Figure 16. Typical lava layers exposed in the wall of a side canyon in Coprates Chasma, Valles Marineris. (a) Portion of HiRISE image PSP_002814_1665 centered at $13.455^{\circ} \mathrm{S}, 303.295^{\circ} \mathrm{E}$. Note that the style of layering changes near the top of the canyon. (b) Close-up of lower stratigraphy showing a repetitive sequence of lava flows.

of the original surface. This morphology is diagnostic of lava inflation [Keszthelyi et al., 2000]. The scale of the features (a few hundred meters across and a few kilometers long) is identical to many terrestrial examples [e.g., Keszthelyi and Pieri, 1993; Mattox et al., 1993; Whitehead and Stephenson, 1998; Keszthelyi et al., 2000]. Lava flow inflation is the lifting of the upper crust by injection of liquid into the molten interior of the flow [Walker, 1991; Hon et al., 1994]. While inflation can occur in any type of lava flow, it is most common in pahoehoe sheet flows [e.g., Self et al., 1998]. It is important because it is indicative of lava transport under a thick insulating crust. While inflation features were hinted at in the lower resolution MOC images [Keszthelyi et al., 2000], it has taken HiRISE resolution to confidently identify them.

[55] The relationship between the inflated sheet flow and the imaged segment of the Cerberus Fossae is somewhat obscure. The lava flows are not seen to flow systematically away from the fissure, but MOLA topography suggests that the area around the fissure is a local topographic high. However, MOLA has particularly poor spatial coverage at these equatorial latitudes, so those elevation data are ambiguous. The HiRISE anaglyph shows no significant topography, but a quantitative DEM is needed to measure the (very shallow) slopes. The depressions along the fissure (Figure 14b) could have formed by collapse over a vent. However, there are no clear indications of lava lakes or spatter ramparts. Instead, there are large inflation features interspersed with the collapse pits (Figure 14b). This suggests an alternative possibility. The imaged portion of the Cerberus Fossae may have been inundated by lavas from another (probably nearby) location. The pits and inflation features may have formed as the lava was emplaced over deep cracks. The lava would be deepest in the fissures, so it would cool there last. Therefore, it is the most likely place for (1) lava flow inflation and (2) late stage draining (laterally or downward) after most of the flow has solidified.

[56] A much more enigmatic example of uplifted/inflated lava flows can be found at the southern margin of Elysium Planitia (Figure 15). In the regional CTX view, many roughly circular uplifts several kilometers across are readily apparent in the southern half of the image (Figure 15a). In the south, the uplifts cease precisely at the southern margin of the platy-ridged lavas. This would suggest that the uplift is a lava flow process. 
[57] However, in the north and east, the more irregular uplifts appear to form in a nonlava lithology. The uplifted material does not exhibit a platy-ridged surface and appears eroded. In the north of Figure 15a, the broad plateau appears to lose volume and leave behind an irregular knobby or pitted terrain (see also the northeast corners of Figures $15 \mathrm{~b}$ and $15 \mathrm{c})$. Visually, the morphology is similar to partially degraded (i.e., "dissected") midlatitude mantling deposit [Mustard et al., 2001]. That degradation is assumed to be the product of sublimation of a mix of dust and ice deposited from the atmosphere. However, such volatile-rich deposits this close to the equator should be sublimated to a depth of many meters [Mellon and Jakosky, 1995; Mellon et al., 1997; Schorghofer and Aharonson, 2005]. In fact, the gamma ray spectrometer aboard Mars Odyssey does not detect any significant concentrations of near-surface hydrogen in the area, requiring any current ice to be at least a meter below the surface [e.g., Feldman et al., 2004]. In adjacent areas, the nonlava uplifts break into blocks a few hundred meters on a side, suggesting that it is not as mechanically strong as the lava (which generally produces intact plateaus).

[58] One possibility is that the uplifts were caused by freezing groundwater, such that these plateaus are essentially pingos about a hundred times larger in lateral extent than terrestrial examples. The heat of the lava would have melted ground ice across a broad area and water might have flowed in the subsurface to this location. Alternatively, the source of the groundwater could be the nearby southern highlands. Deep groundwater would find itself close to the surface as it moved past the dichotomy boundary. The topographic setting is very similar to locations where hydraulic pingos are found on the Earth, but the scale of the topography (and the potential pingos) is much larger on Mars. As the pressurized groundwater froze, the surface would have been uplifted. The flow of groundwater into the surrounding nonlava materials could explain the uplift and degradation of those areas. However, these hypotheses are difficult to reconcile with the abrupt termination of uplift to the south at the flow margin.

[59] Our preferred hypothesis is that these are lava inflation features, on a scale never reported on the Earth. Furthermore, the lava was emplaced underneath the (presently discontinuous) weaker materials such that this overlying material was uplifted with the lava surface. This is most strongly supported by a totally enclosed $5 \times 10 \mathrm{~km}$ depression that is filled with platy-ridged lava (Figure 15b). There is no hint of a volcanic vent within this depression. At the same time, there are flow margins within the depression that show that the lava embayed the local topographic highs. Thus, the depression had roughly its current form when the lava filled it, but the source of the lava is outside this closed depression.

[60] There are two possible explanations for how the actively inflating lava flow came to be underneath the overlying weaker material: either (1) the overlying layer was deposited while the lava flow was active or (2) the lava was able to intrude underneath poorly consolidated, low density, sediments. Such "invasive" lava flows have been repeatedly reported on the Earth, especially in flood basalt provinces, but have been difficult to confirm because of the discontinuous and somewhat enigmatic outcrops [e.g., Byerly and Swanson, 1978; Beeson et al., 1979; Wells et al., 1989; Beresford and Cas, 2001; Lewis et al., 2005]. Alternatively, if the overlying weak material is composed of volcanic ash, it is eminently reasonable to have the mantle deposited at the same time as the lava flow is actively fed by the eruption. In fact, comparison to large terrestrial basaltic eruptions leads one to expect voluminous ash deposits to be associated with Martian flood basalt eruptions [e.g., Keszthelyi et al., 2000].

[61] In either the invasive or syndepositional models, lava traveling and inflating under the sediment would disrupt the surface, producing the 100-m-scale tilted blocks. If there were patches of ice in the sediment, especially at a depth of several meters, it would be mobilized by the heat of the lava flow, producing the "degraded" hummocky surfaces. Much of the large volume of volcanic gases released in a Martian flood basalt eruption [e.g., Plescia, 1993; Thordarson et al., 2008] could be expected to freeze onto the volcanic ash particles and thus be incorporated into the mantling deposit.

[62] The HiRISE observation in this area (Figure 15c) shows additional details important in understanding the emplacement of this lava flow. In this location, the lava surfaces on the uplifted and level parts of the lava flow are not contiguous (Figure 15d). The formation of a pressure ridge parallel to the uplift's margin indicates that the topographically lower flow abutted against the uplift. This indicates that, in this area, the region between the uplifted plateaus was embayed by later lava. This is actually common behavior in inflated flow fields. The liquid lava within inflation features can often break out through cracks in the upper crust [e.g., Self et al., 1998]. Embayment relations like these are common on Hawaiian inflated pahoehoe flow fields, albeit at a much smaller scale [e.g., Mattox et al., 1993; Hon et al., 1994]. A similar breakout from within an inflating lava flow is the simplest explanation for the lava in the enclosed depression seen in Figure 15b.

[63] In some ways more intriguing is the presence of 10- to 30-m-scale uplifts on the uplifted lava surface (Figure 15e). These features are of exactly the same scale as typical terrestrial tumuli (isolated lava inflation features) [Walker, 1991; Hon et al., 1994; Rossi and Gudmundsson, 1996]. The pattern of medial and circumferential cracks is also typical of terrestrial tumuli. The resolution of the HiRISE images will allow this field of potential tumuli can be quantitatively investigated, for example examining the spatial distribution following the techniques described by Glaze et al. [2005].

[64] If these are tumuli, and the kilometer-scale uplifts are also caused by lava inflation, inflation must have operated at two very different times during the emplacement of a single flow. The thickness of the crust that is uplifted in the tumuli can be seen to be only a few meters thick (Figure 15e). A crust of this thickness would form in a matter of a few days. However, the solid crust atop the large uplifts was at least 20-30 m thick, as determined from shadow measurements in Figure 15d. Many months of cooling are required for such a thick crust to form.

[65] We end the discussion of Martian flood lavas with a cross-sectional view in the walls of Valles Marineris. Figure 16 shows a very typical exposure. The middle part of the exposed stratigraphy is composed entirely of a sequence of similar lava flows (Figure 16b). The view is uncannily similar to exposures of flood basalt lava flows on Earth [McEwen et al., 1999; Keszthelyi and McEwen, 
2007]. By analogy with the terrestrial examples, the bouldery cliffs are interpreted to be the resistant dense cores of lava flows. The vesicular or brecciated flow tops erode more easily, producing the interleaving slopes. As on Earth, it is difficult to trace individual flows for more than a few kilometers because of the lateral extent of good exposure. However, the sampling provided by HiRISE to date suggests that the package of lava flows does not change character in any fundamental way over distances of at least hundreds of kilometers. The layers mostly show a $\sim 50 \mathrm{~m}$ wide extent in this nadir image. MOLA topography indicates that the slope is approximately $28^{\circ}$, so the lava flows are $\sim 25 \mathrm{~m}$ thick. As on Earth, the resistant core of the flow appears to make up roughly half the flow thickness. Scree and eolian deposits hide the details of the contacts between the flows, but the main lava sequence is reassuringly similar to terrestrial flood basalt provinces.

[66] The upper few hundred meters is more puzzling. The stratigraphy transitions to thin discontinuous beds of hard rock within a massive and relatively easily eroded matrix. This sequence is capped by a thick resistant bed that can be traced across the entire region [Beyer and McEwen, 2005]. The resistant bed appears very similar to the flood lava flows deeper in the section. The very top of the canyon wall is a thick deposit of poorly consolidated weak material, some of which is being eroded by the wind. This mantling unit may be similar to the upper unit observed on Olympus Mons (Figure 9). One possible interpretation is that the upper part of this stratigraphic stack records the waning of volcanism in the region with only one recent flood lava eruption [Beyer and McEwen, 2005]. The thinner, discontinuous, beds might be ejecta from impact craters rather than thin lava flows which would have difficulty traveling the great distances to the nearest recognizable volcanic vents. Those impact craters would be largely buried by the final flood lava flow, making this a difficult hypothesis to test.

[67] Alternatively, the change in character in the upper part of the canyon could be the result of extensive weathering of the upper section. The capping resistant bed would be a relatively recent and pristine lava flow. The lack of a clear signature of weathering minerals in the upper part of Valles Marineris in previous publications [e.g., Christensen et al., 2001, 2003] leads us to disfavor this hypothesis.

\section{Conclusions}

[68] HiRISE has demonstrated the great utility of very high spatial resolution imaging, especially with color and stereo, in the study of Mars volcanism. It has found unequivocal evidence for inflation and the roofing of channels. It also has found new evidence in support of previous suggestions of widespread and diverse pyroclastic deposits. The key to fully exploiting HiRISE's capabilities is finding exceptional exposures where meter-scale volcanic features are not obscured by secondary processes. Often the MRO CTX camera provides a near-ideal balance of spatial resolution and coverage for studying volcanic features. However, the best science is achieved when the two instruments work together synergistically.

[69] Acknowledgments. We gratefully acknowledge the support of the NASA Mars Reconnaissance Orbiter project managed through the
California Institute of Technology's Jet Propulsion Laboratory. Special thanks to the CTX team and Malin Space Science Systems for the context images. The authors would also like to acknowledge the invaluable assistance of the entire HiRISE team, including the software developers, uplink and downlink teams, and the science team all of whom have actively participated in many discussions that have helped shape this paper.

\section{References}

Anderson, J. A., S. C. Sides, D. L. Soltesz, T. L. Sucharski, and K. J. Becker (2004), Modernization of the integrated software for images and spectrometers, Lunar Planet. Sci. Conf., 35, Abstract 2039.

Becker, K. J., J. A. Anderson, S. C. Sides, E. A. Miller, E. M. Eliason, and L. P. Keszthelyi (2007), Processing HiRISE images using ISIS3, Lunar Planet. Sci. Conf., 38, Abstract 1779

Beeson, M. H., R. Perttu, and J. Perttu (1979), The origin of the Miocene basalt of coastal Oregon and Washington: An alternative hypothesis, Oreg. Geol., 41, 159-166.

Beresford, S. W., and R. A. F. Cas (2001), Komatiitic invasive lava flows, Kambalda, western Australia, Can. Mineral., 39, 525-535.

Beyer, R. A., and A. S. McEwen (2005), Layering stratigraphy of eastern Coprates and northern Capri Chasmata, Mars, Icarus, 179, 1-23.

Bridges, N. T., P. E. Geissler, A. S. McEwen, B. J. Thomson, F. C. Chuang, K. E. Herkenhoff, L. P. Keszthelyi, and S. Martínez-Alonso (2007), Windy Mars: A dynamic planet as seen by the HiRISE camera, Geophys. Res. Lett., 34, L23205, doi:10.1029/2007GL031445.

Burr, D. M., J. A. Grier, A. S. McEwen, and L. P. Keszthelyi (2002), Repeated aqueous flooding from the Cerberus Fossae: Evidence for very recently extant deep groundwater on Mars, Icarus, 159, 53-73.

Byerly, G. R., and D. A. Swanson (1978), Invasive Columbia River basalt flows along the northwestern margin of the Columbia Plateau, northcentral Washington, Geol. Soc. Am. Abstr. Programs, 10, 98.

Carr, M. H. (1974), The role of lava erosion in the formation of lunar rilles and Martian channels, Icarus, 22, 1-23.

Carr, M. H. (1980), The morphology of the Martian surface, Space Sci. Rev., 25, 231-284.

Carr, M. H. (1996), Water on Mars, 229 pp., Oxford Univ. Press, New York. Carr, M. H., and R. Greeley (1980), Volcanic features of Hawaii: A basis for comparison with Mars, NASA Spec. Publ., SP-403, 211 pp.

Cattermole, P. (1986), Linear volcanic features at Alba Patera, Mars: Probable spatter ridges, Proc. Lunar Planet. Sci. Conf. 17th, Part 1, J. Geophys. Res., 91, suppl., E159-E165.

Chapman, M. G., G. Neukum, S. C. Werner, S. van Gasselt, A. Dumke, W. Zuschneid, and G. Michael (2007), Echus Chasma and Kasei Valles, Mars: New data and geologic interpretations, Lunar Planet. Sci. Conf., 38, Abstract 1407.

Christensen, P. R. (1986), Regional dust deposits on Mars: Physical properties, age, and history, J. Geophys. Res., 91, 3533-3545.

Christensen, P. R., et al. (2001), Mars Global Surveyor Thermal Emission Spectrometer experiment: Investigation description and surface science results, J. Geophys. Res., 106, 23,823-23,871.

Christensen, P. R., et al. (2003), Morphology and composition of the surface of Mars: Mars Odyssey THEMIS Results, Science, 300, 2056-2060.

Dundas, C. M., L. P. Keszthelyi, A. S. McEwen, and the HiRISE Team (2007), Initial HiRISE observations of cratered cone groups on Mars, Lunar Planet. Sci. Conf., 38, Abstract 2116.

Fagents, S. A., and L. Wilson (1996), Numerical modeling of ejecta dispersal from transient volcanic explosions on Mars, Icarus, 123, 284-295.

Feldman, W. C., et al. (2004), Global distribution of near-surface hydrogen on Mars, J. Geophys. Res., 109, E09006, doi:10.1029/2003JE002160.

Glaze, L. S., S. W. Anderson, E. R. Stofan, S. Baloga, and S. E. Smrekar (2005), Statistical distribution of tumuli on pahoehoe flow surfaces: Analysis of examples in Hawaii and Iceland and potential applications to lava flows on Mars, J. Geophys. Res., 110, B08202, doi:10.1029/2004JB003564.

Greeley, R., and B. D. Schneid (1991), Magma generation on Mars: Amounts, rates, and comparisons with Earth, Moon, and Venus, Science, 254, 996-998.

Greeley, R., S. A. Fagents, R. S. Harris, S. D. Kadel, and D. A. Williams (1998), Erosion by flowing lava: Field evidence, J. Geophys. Res., 103, $27,325-27,345$.

Heliker, C. C., M. T. Mangan, T. N. Mattox, J. P. Kauahikaua, and R. T. Helz (1998), The character of long-term eruptions: Inferences from episodes $50-53$ of the Puu Oo-Kupaianaha eruption of Kilauea Volcano, Bull. Volcanol., 59, $381-393$.

Holcomb, R. T. (1987), Eruptive history and long-term behavior of Kilauea Volcano, U.S. Geol. Surv. Prof. Pap., 1350, 261-350.

Hon, K., J. Kauahikaua, R. Denlinger, and K. Mackay (1994), Observations and measurements of active lava flows on Kilauea Volcano, Hawaii, Geol. Soc. Am. Bull., 106, 351-370.

Hulme, G. (1973), Turbulent lava flows and the formation of lunar sinuous rilles, Mod. Geol., 4, 107-117. 
Hulme, G. (1982), A review of lava flow processes related to the formation of lunar sinuous rilles, Geophys. Surv., 5, 245-279.

Jaeger, W. L., L. P. Keszthelyi, A. S. McEwen, C. M. Dundas, and P. S. Russell (2007), Athabasca Valles, Mars: A lava-draped channel system, Science, 317, 1709-1711.

Keszthelyi, L., and A. S. McEwen (2007), Comparison of flood lavas on Earth and Mars, in The Geology of Mars: Evidence from Earth-Based Analogs, edited by M. Chapman, pp. 126-150, Cambridge Univ. Press, New York.

Keszthelyi, L. P., and D. C. Pieri (1993), Emplacement of the $75 \mathrm{~km}-$ long Carrizozo lava flow fields, south-central New Mexico, J. Volcanol. Geotherm. Res., 59, 59-75.

Keszthelyi, L., A. S. McEwen, and T. Thordarson (2000), Terrestrial analogs and thermal models for Martian flood lavas, J. Geophys. Res., 105, $15,027-15,050$

Keszthelyi, L., T. Thordarson, A. McEwen, H. Haack, M.-N. Guilbaud, S. Self, and M. J. Rossi (2004), Icelandic analogs to Martian flood lavas, Geochem. Geophys. Geosyst., 5, Q11014, doi:10.1029/2004GC000758.

Kirk, R. L., et al. (2007), Ultrahigh resolution topographic mapping of Mars with HiRISE stereo images: Methods and first results, Lunar Planet. Sci. Conf., 38, Abstract 1428 .

Lancaster, N. (1989), The dynamics of star dunes: An example from the Gran Desierto, Mexico, Sedimentology, 36, 273-289.

Lewis, R. S., J. H. Bush, R. F. Rumester, J. D. Kauffman, D. L. Garwood, P. E. Myers, and K. L. Othberg (2005), Geologic map of the Potlatch $30 \times$ 60 minute quadrangle, Idaho, Idaho Geol. Surv. Geol. Map, 41, 30 pp.

Lipman, P. W., and N. G. Banks (1987), Aa flow dynamics, Mauna Loa 1984, U.S. Geol. Surv. Prof. Pap., 1350, 1527-1567.

Malin, M. C., et al. (2007), Context Camera Investigation on board the Mars Reconnaissance Orbiter, J. Geophys. Res., 112, E05S04, doi:10.1029/2006JE002808.

Mattox, T. N., C. Heliker, J. Kauahikaua, and K. Hon (1993), Development of the 1990 Kalapana Flow Field, Kilauea Volcano, Hawaii, Bull. Volcanol., 55, 407-413.

McEwen, A. S., M. C. Malin, M. H. Carr, and W. K. Hartmann (1999), Voluminous volcanism on early Mars revealed in Valles Marineris, Nature, $397,584-586$.

McEwen, A. S., et al. (2007), Mars Reconnaissance Orbiter's High Resolution Imaging Science Experiment (HiRISE), J. Geophys. Res., 112, E05S02, doi:10.1029/2005JE002605.

McGovern, P. J., J. K. Morgan, and M. A. Higbie (2006), Structure and evolution of the Olympus Mons volcanic edifice and basal escarpment, Mars, Lunar Planet. Sci. Conf., 37, Abstract 2329.

Mellon, M. T., and B. M. Jakosky (1995), The distribution and behavior of Martian ground ice during past and present epochs, J. Geophys. Res., $100,11,781-11,799$

Mellon, M. T., B. M. Jakosky, and S. E. Postawko (1997), The persistence of equatorial ground ice on Mars, J. Geophys. Res., 102, 19,357-19,369.

Mouginis-Mark, P. (1990), Recent melt water release in the Tharsis region of Mars, Icarus, 84, 362-373.

Mouginis-Mark, P. J., and P. R. Christensen (2005), New observations of volcanic features on Mars from the THEMIS instrument, J. Geophys. Res., 110, E08007, doi:10.1029/2005JE002421.

Murchie, S., et al. (2007), Compact Reconnaissance Imaging Spectrometer for Mars (CRISM) on Mars Reconnaissance Orbiter (MRO), J. Geophys. Res., 112, E05S03, doi:10.1029/2006JE002682.
Mustard, J. F., C. D. Cooper, and M. K. Rifkin (2001), Evidence for recent climate change on Mars from the identification of youthful near-surface ground ice, Nature, 412, 411-414.

Okubo, C. H., and S. J. Martel (1998), Pit crater formation on Kilauea Volcano, Hawaii, J. Volcanol. Geotherm. Res., 86, 1-18.

Plescia, J. B. (1993), An assessment of volatile release from recent volcanism in Elysium, Mars, Icarus, 104, 20-32.

Rossi, M. J., and A. Gudmundsson (1996), The morphology and formation of flow-lobe tumuli on Icelandic shield volcanoes, J. Volcanol. Geotherm. Res., 72, 291-308.

Schorghofer, N., and O. Aharonson (2005), Stability and exchange of subsurface ice on Mars, J. Geophys. Res., 110, E05003, doi:10.1029/ 2004JE002350.

Schubert, G., R. E. Lingenfelter, and S. J. Peale (1970), The morphology, distribution, and origin of lunar sinuous rilles, Rev. Geophys., 8, 199-224

Self, S., L. Keszthelyi, and T. Thordarson (1998), The importance of pahoehoe, Annu. Rev. Earth Planet. Sci., 26, 81-110.

Steno, N. (1669), De solido intra solidum naturaliter contento dissertationis prodromus, Florence, Maar, II, 181-227.

Thordarson, T., M. Rampino, L. Keszthelyi, and S. Self (2008), Effects of mega-scale eruptions on Earth and Mars, Spec. Pap. Geol. Soc. Am., in press

Tornabene, L. L., A. S. McEwen, G. R. Osinski, P. J. Mouginis-Mark, J. M. Boyce, R. M. E. Williams, J. J. Wray, J. A. Grant, and the HiRISE Team (2007), Impact melting and the role of subsurface volatiles: Implications for the formation of valley networks and phyllosilicate-rich lithologies on early Mars, Int. Mars Conf., 7, Abstract 3288.

Wadge, G. (1981), The variations of magma discharge during basaltic eruptions, J. Volcanol. Geotherm. Res., 11, 139-168.

Walker, G. P. L. (1972), Compound and simple lava flows and flood basalts, Bull. Volcanol., 35, 579-590.

Walker, G. P. L. (1991), Structure, and origin by injection of lava under surface crust, of tumuli, "lava rises" "lava-rise pits", and "lava-inflation clefts" in Hawaii, Bull. Volcanol., 53, 546-558.

Wells, R. E., R. W. Simpson, R. D. Bentley, M. H. Beeson, M. T. Mangan, and T. L. Wright (1989), Correlation of Miocene flows of the Columbia River Basalt Group from the central Columbia River Plateau to the coast of Oregon and Washington, Spec. Pap. Geol. Soc. Am., 239, 113-130.

Whitehead, P. W., and P. J. Stephenson (1998), Lava rise ridges of the Toomba basalt flow, north Queensland, Australia, J. Geophys. Res., $103,27,371-27,382$.

Williams, D. A., R. Greeley, E. Hauber, K. Gwinner, and G. Neukum (2005), Erosion by flowing Martian lava: New insights for Hecates Tholus from Mars Express and MER data, J. Geophys. Res., 110, E05006, doi:10.1029/2004JE002377.

Wilson, L., and J. W. Head III (1994), Mars: Review and analysis of volcanic eruption theory and relationships to observed landforms, Rev. Geophys., 32, 221-263.

Wood, C. A. (1979), Monogenetic volcanoes of the terrestrial planets, Proc. Lunar Planet. Sci Conf., 10th(3), 2815-2840.

R. A. Beyer, Carl Sagan Center at the SETI Institute, Mountain View, CA 94035, USA.

C. Dundas, A. McEwen, and L. Tornabene, Lunar and Planetary Laboratory, University of Arizona, Tucson, AZ 85721, USA

W. Jaeger, L. Keszthelyi, and M. Milazzo, U.S. Geological Survey, 2255

N. Gemini Drive, Flagstaff, AZ 86001, USA. (laz@usgs.gov) 